\title{
A study of the ndt techniques using ultrasonic pulse velocity test and microwave oven method on SCC and TVC
}

Dana Dashti

Follow this and additional works at: https://researchrepository.wvu.edu/etd

\section{Recommended Citation}

Dashti, Dana, "A study of the ndt techniques using ultrasonic pulse velocity test and microwave oven method on SCC and TVC" (2016). Graduate Theses, Dissertations, and Problem Reports. 5437.

https://researchrepository.wvu.edu/etd/5437

This Thesis is protected by copyright and/or related rights. It has been brought to you by the The Research Repository @ WVU with permission from the rights-holder(s). You are free to use this Thesis in any way that is permitted by the copyright and related rights legislation that applies to your use. For other uses you must obtain permission from the rights-holder(s) directly, unless additional rights are indicated by a Creative Commons license in the record and/ or on the work itself. This Thesis has been accepted for inclusion in WVU Graduate Theses, Dissertations, and Problem Reports collection by an authorized administrator of The Research Repository @ WVU. For more information, please contact researchrepository@mail.wvu.edu. 


\title{
A STUDY OF THE NDT TECHNIQUES USING ULTRASONIC PULSE VELOCITY TEST AND MICROWAVE OVEN METHOD ON SCC AND TVC
}

\section{Dana Dashti}

\author{
Thesis Submitted to the \\ Benjamin M. Statler College of Engineering and Mineral Resources \\ at West Virginia University
}

in Partial Fulfillment of the Requirements for the Degree of

Master of Science in

Civil Engineering

Roger Chen, Ph. D., Chair

Radhey Sharma, Ph.D.

P. V. Vijay, Ph. D

Department of Civil and Environmental Engineering

Morgantown, West Virginia

2016

Keywords: Self-Consolidating Concrete; W/cm; Microwave Method; Nondestructive Testing; UPV 


\title{
ABSTRACT
}

\section{A STUDY OF THE NDT TECHNIQUES USING ULTRASONIC PULSE VELOCITY TEST AND MICROWAVE OVEN METHOD ON SCC AND TVC}

\author{
Dana Dashti
}

In this study, two nondestructive testing (NDT) techniques were investigated to study the ultrasonic pulse velocity and water cement ratio of self-consolidating concrete (SCC) and traditional vibrated concrete (TVC). The ultrasonic pulse velocity test is one of the most useful nondestructive methods to determine the properties of concrete. It is also important in structural engineering where it can detect defects and determine deterioration. In order to reach these purposes, there are several ultrasonic wave propagation characteristics that should be taken under consideration such as: velocity, attenuation, frequency, and energy. For the purpose of this study, 3 specimens from each mix design batch of conventional and self-consolidating concrete were tested in the laboratory at $1,3,7,14$, and 28 days after their casting to measure the pulse velocity and the compressive strength. The relationship between the pulse velocity and Young's modulus of those concrete specimens was determined. The ultrasonic pulse velocity test can be performed with a simple setting that includes: two transducers, a pulser-reciever unit, and the data acquisition system. The two transducers were to conduct direct transmission. Test results showed that dynamic Young's modulus could be obtained from the wave velocity measurement but the dynamic Young's modulus is higher than those static Young's modulus calculated from the compressive strength for both conventional and self-consolidating concrete. The results also show that self-consolidating concrete has higher compressive strength at early ages compared to conventional concrete.

Since the self-consolidating concrete (SCC) is highly influenced by the changes in water content, it is important to develop on-site methods to determine water to cement ratio, which would be useful for on-site applications. In this thesis, the standard method for water content of freshly mixed concrete using microwave method was tested on both conventional concrete and SCC to determine their on-site water to cement ratio. Two testing procedures were used following AASHTO T318-02, which included the use of non-sieved concrete samples and sieved concrete sample. Both methods were used to determine the $\mathrm{w} / \mathrm{cm}$ ratio for the conventional Fly Ash concrete and SCC with different accuracy ranges between the two. The average error for TVC is $5.13 \%$ and for SCC is $10.35 \%$ using non-sieved concrete samples. However, the results showed that the current method using sieved concrete samples would not provide the same accuracy. The modified method using sieved concrete samples for both SCC and conventional concrete samples provided higher error because the sieved method provides an inaccurate amount of cement powder being extracted. 


\section{Acknowledgment}

I would like to acknowledge and express my gratitude toward my teacher and advisor Dr. Roger Chen for the knowledge and help that I have received from him throughout the past two years. I would also like to thank my committee members Dr. Radhey Sharma and Dr. P. V. Vijay for their guidance. I would also like to thank my friends and colleagues Mariam Albaghli, Zhanxiao Ma, Guadalupe Leon, and Navid Mardmomen for all the time and effort they have spent in providing me with help and support. I would also like to thank Euclid Chemical and BASF for providing all the materials needed for the completion of this research.

I would like to acknowledge the support that I have received from my country, Kuwait, by providing me with the scholarship so that I could continue my studies. Most importantly, I would like to thank my family and close friends for the love, support and help that they provided me with which encouraged me to give my best and complete this research. 


\section{Table of Contents}

Acknowledgment ..............................................................................................................................................................

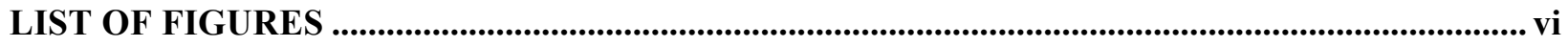

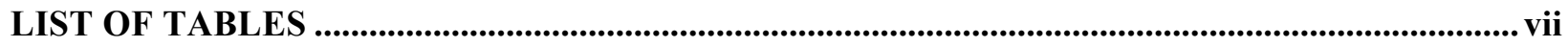

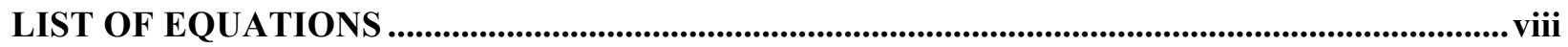

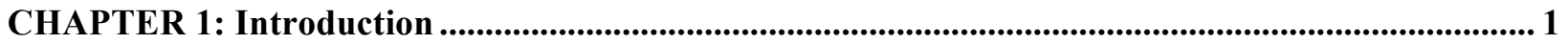

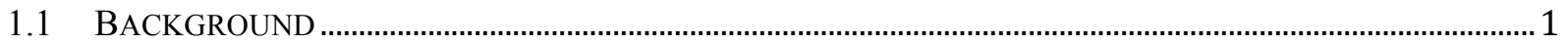

1.1.1 SCC

1.1.2 NDT

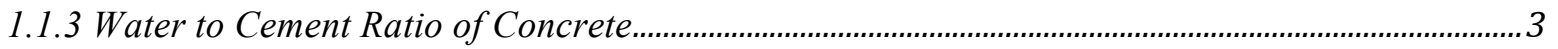

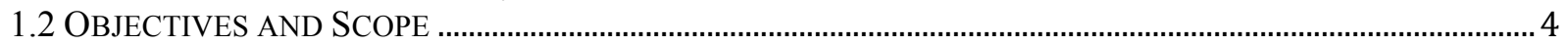

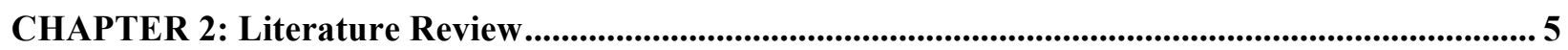

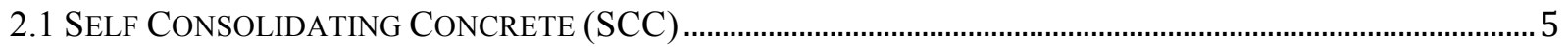

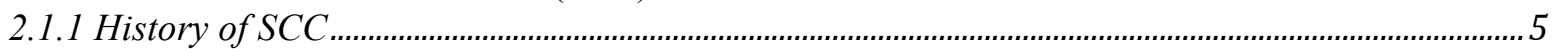

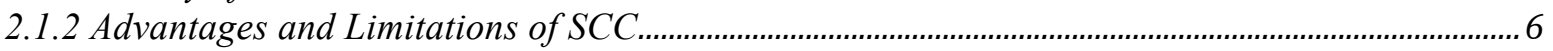

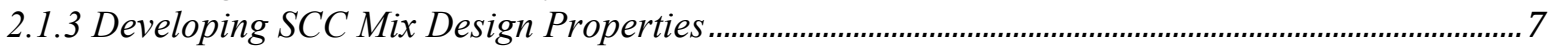

2.1.4 Test Methods of SCC

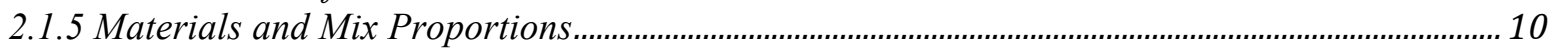

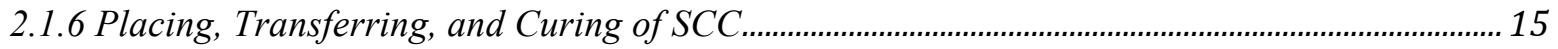

2.1.7 Mechanical Properties of SCC

2.1 WATER TO CEMENT RATIO OF CONCRETE (W/C) ………..................................................................... 21

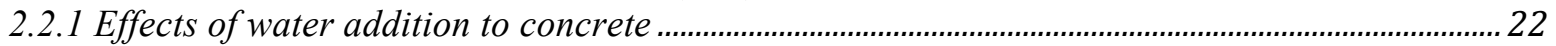

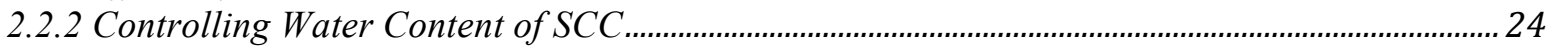

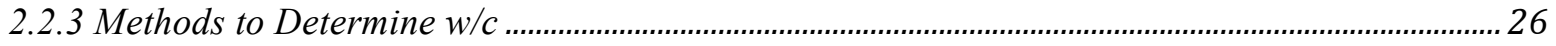

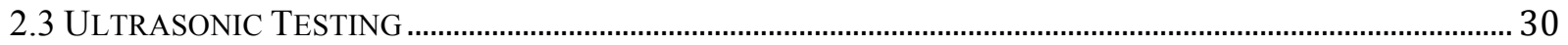

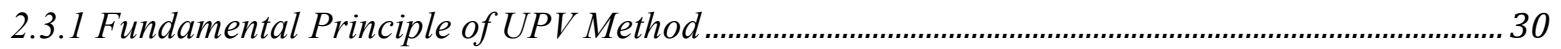

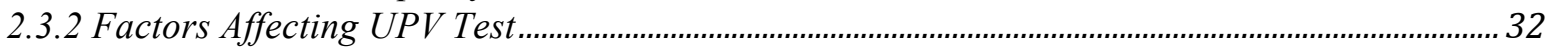

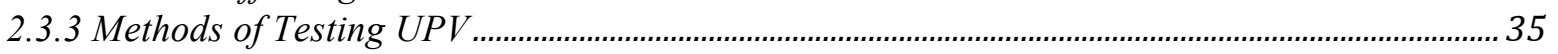

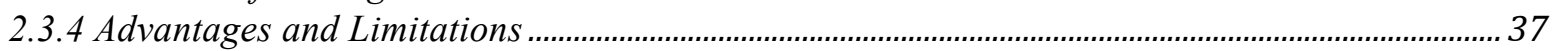

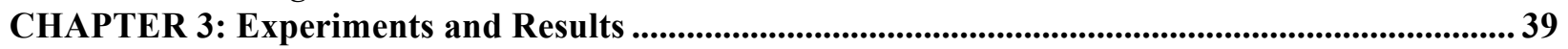

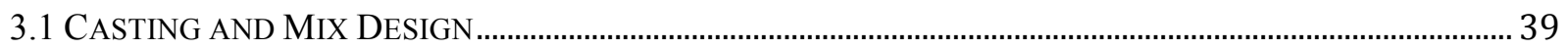

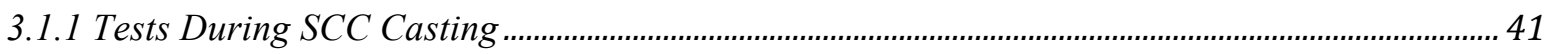

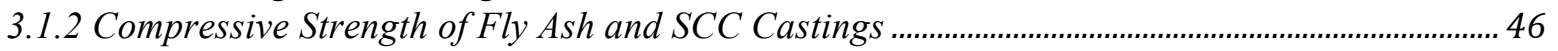

3.2 MiCROWAVE TEST TO DETERMINE W/C ....................................................................................................... 47

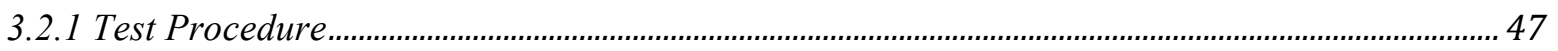

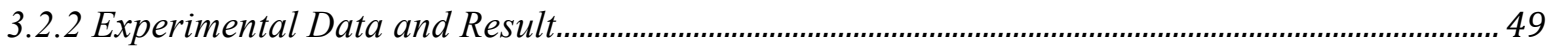

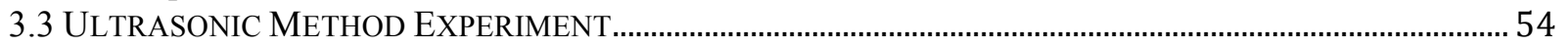

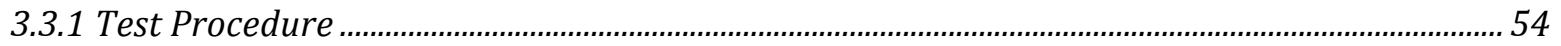

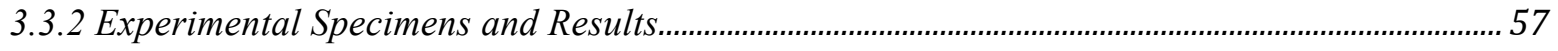

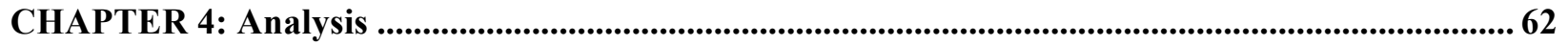

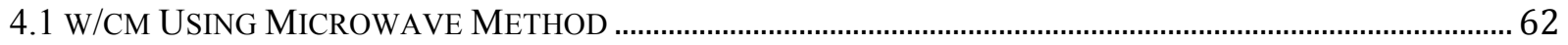

4.1.1 Calculated Concrete Samples and Calculated Sieved samples ......................................................62

4.1.2 Relationship Between Water Evaporation and Time in Microwave ............................................ 63 


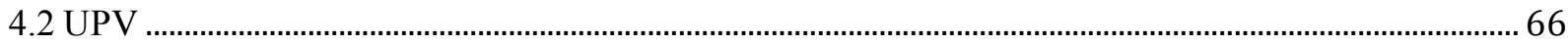

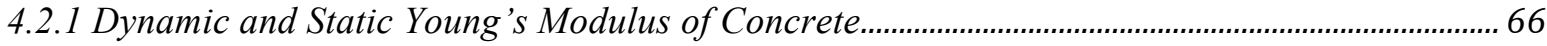

4.2.3 FEM Modeling of Concrete Specimens Using ABAQUS ............................................................. 70

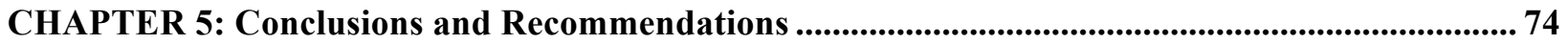

5.1 Determination of Water Cement Ratio Using Microwave Method ....................................... 74

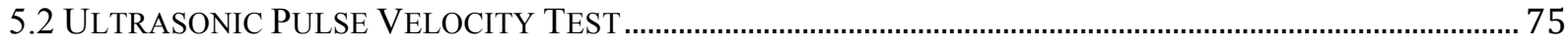

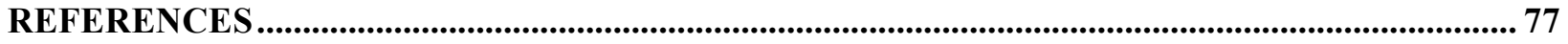

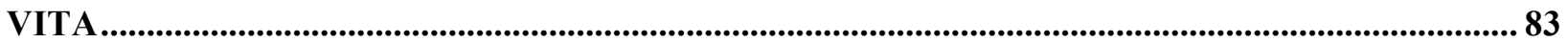




\section{LIST OF FIGURES}

Figure 2.1 - VSI Criteria (ASTM, 2014) ……………………………………………………..... 10

Figure 2.2 - Effect of water addition to the compressive strength. (About concrete, 1995) ...........22

Figure 2.3 - effects of w/c on UPV results (Ye, 2004) ..................................................................... 33

Figure 2.4 - (a) direct, (b) Semi-direct, (c) Indirect (Kaouther, 2014) …………………………….... 37

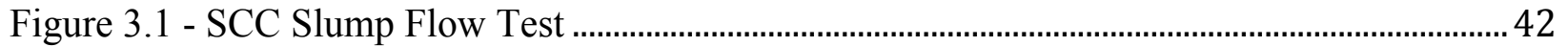

Figure 3.2 - Visual Stability Index Values (ASTM, 2014). ................................................................. 43

Figure 3.3 - SCC Slump flow Final Spread ....................................................................................... 44

Figure 3.4 - SCC J-ring Test …………………………………………………………………... 45

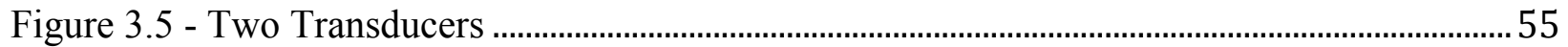

Figure 3.6 - A pulser-receiver unit and a data acquisition system (Bitscope) ...................................55

Figure 3.7 - Main Display of Bitscope …………………………………………………………....56

Figure 3.8 - Wave speed vs. Time of Fly Ash Concrete...................................................................5 58

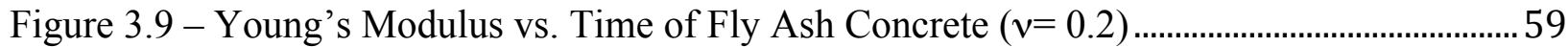

Figure 3.10 - Wave speed vs. Time of SCC...…………………………………………………...6

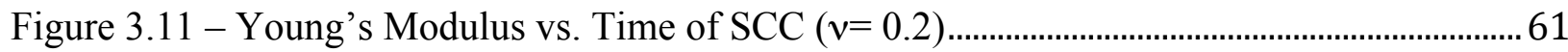

Figure 4.1 (a) - w/cm of Concrete samples …………………………………………………….....6 62

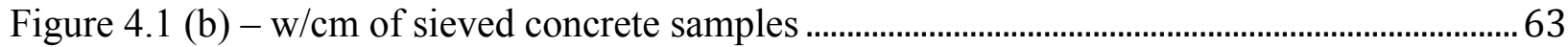

Figure 4.2 - Water Evaporation vs. Time in Microwave for Fly Ash concrete samples ..................64

Figure 4.3 - Water Evaporation vs. Time in Microwave for SCC samples..........................................64

Figure 4.4 - Change in Weight vs. Microwave Time for Fly Ash Concrete samples........................65

Figure 4.5 - Change in Weight vs. Microwave Time for SCC samples...............................................65

Figure 4.6 - Strength vs. wave speed of Fly Ash Concrete specimens .................................................68

Figure 4.7 - Strength vs. wave speed of SCC specimens ………………………………………....69

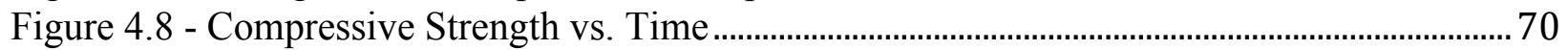

Figure 4.9 - Resulted model of Fly Ash specimen Using 25 Elements in ABAQUS........................71

Figure 4.10 - Resulted model of SCC specimen Using 100 Elements in ABAQUS ......................... 71

Figure 4.11 - Loading pulse function................................................................................................... 73

Figure 4.12 - ABAQUS results using 25 elements and 100 elements ............................................... 73 


\section{LIST OF TABLES}

Table 2.1 - Fresh properties requirements for site acceptance of Class S-P concrete (Chen et. al., 2012)

Table 2.2 - Typical moisture ranges for concrete aggregates (Controlling water in self

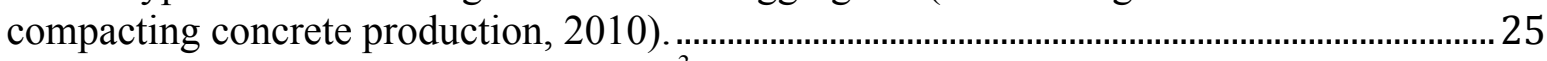

Table 3.1 - Theoretical Mix Design for $1.8 \mathrm{ft}^{3}$ Conventional Concrete............................................. 40

Table 3.2 - Theoretical Mix Design for 1.8- $\mathrm{ft}^{3} \mathrm{SCC}$..................................................................... 41

Table 3.3 - Blocking Assessment (ASTM, 2014) ……………………………………………….... 45

Table 3.4 - Compressive Strength of conventional concrete and SCC............................................... 46

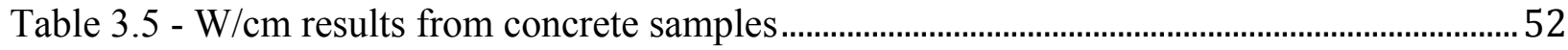

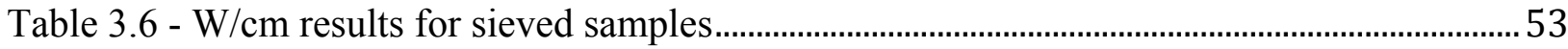

Table 3.7 - Ultrasonic Wave Velocity Results of Fly Ash (Sample \#3).............................................57

Table 3.8 - Ultrasonic Velocity Results of SCC (Sample \#3) ……………………………………......59

Table 4.1 - Static and Dynamic Young's Modulus of Fly ash...............................................................66

Table 4.2 - Static and Dynamic Young's Modulus of SCC.................................................................67 


\section{LIST OF EQUATIONS}

EQUATION (1) used to explain the relationship between $\mathrm{w} / \mathrm{c}$ and strength in concrete.........23

EQUATION (2) used to calculate the compressive wave velocity.......................... 31

EQUATION (3) used to calculate the moisture content of sample...............................

EQUATION (4) used to calculate the slump flow.....................................42

EQUATION (5) used to calculate the water content of sample as a percentage.................48

EQUATION (6) used to calculate the sample free water in grams.........................49

EQUATION (7) used to calculate the theoretical sample cementitious content in grams.........50

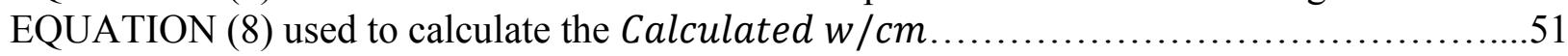

EQUATION (9) used to calculate the error of the test results with relation to the actual

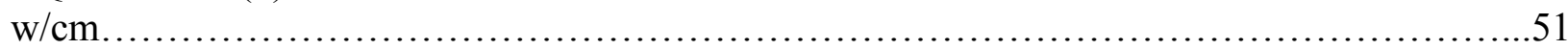

EQUATION (10) used to calculate the static young's modulus...............................66

EQUATION (11) used to represent the relationship between strength and velocity............67

EQUATION (12) used to represent the relationship between strength and velocity............67

EQUATION (13) used to represent the relationship between strength and velocity............68

EQUATION (14) used to represent the relationship between strength and velocity............68 


\section{CHAPTER 1: Introduction}

\subsection{Background}

Concrete is known as one of the basic materials in most of the engineering projects. There are many different variables that could affect the performance of concrete such as: water to cement ratio, type and size of aggregates, temperature, relative humidity and curing of concrete. The behavior of the mechanical properties of concrete such as the compressive strength is correlated by those variables. In this thesis, two types of concrete were tested; two different experiments were done on both conventional concrete and self-consolidating concrete to determine the relationship between those properties and variables. Self-Consolidating concrete (SCC) is a new type of concrete that is highly flowable and has the ability to spread and fill the formwork without any external compaction. As compared to traditional vibrated concrete (TVC), the cost of SCC material is slightly higher since it requires more cement and chemical admixtures, but it would save construction time and effort by requiring less labor, therefore the total cost can be less than TVC.

\subsubsection{SCC}

Self-consolidating concrete (SCC) is a highly flowable, non-segregating concrete (where the coarse aggregate and the cement paste aren't separated). It has the ability to fill the formwork and spread without the need of an external consolidation (Self Consolidating Concrete, 2004). Other than being highly flowable, the SCC has a passing ability and it is considered to be a very stable kind of concrete. SCC is considered to be stable since it would remain homogenous and wouldn't segregate. There are two different kinds of stability; dynamic stability: which means 
the concrete would stay stable during transferring and placing, and static stability: which means when the concrete is already placed but not hardened yet, the aggregate wouldn't be steady and it doesn't bleed. When making SCC, high range water reducers (which makes it a highly flowable material) and more fine materials are used. A very high strength concrete with a low permeability can be achieved by proportioning it for low water-cement ratios.

The SCC is known as a valuable material in construction where it flows through tight spaces which may otherwise be impossible to cast and can flow into complicated areas such with heavily reinforcing bars or in areas where there can be no access to vibrators. (Palmer, Self-Consolidating Concrete, 1999).

\subsubsection{NDT}

Non-Destructive testing (NDT) is known as a quality control method. It can be used to determine the properties of a material, system or component without destroying the material that is being tested. The non-destructive testing uses: infrared radiation, radiography, ultrasound, $\mathrm{x}-$ rays, and many other techniques to inspect material properties, structural flaws, and other kinds of material defects. The techniques used in NDT testing are usually easy and fast methods that don't require a lot of wait and calculations. Those techniques could be used in high-risk areas such as: nuclear and sea shore structures, gas and oil pipelines.

Non-destructive tests are considered very useful since they can be used to control manufacturing processes, insure product integrity, lower production cost, and maintain the material quality level. There are many testing methods that are considered as non-destructive methods and here are some examples: Ground Penetrating Radar (GPR), Laser Testing Methods 
(LM), and Ultrasonic Testing (UT). The ultrasonic pulse velocity technique has the lowest cost of use when compared with other non-destructive methods and it is convenient and takes less time to employ (Gebretsadik B. T., 2003) (CARINO, 2004).

\subsubsection{Water to Cement Ratio of Concrete}

The water-cement ratio is defined as the ratio of the weight of water to the weight of cement used in the concrete mix. A w/c ratio of 0.2 means that for every $100 \mathrm{lbs}$ of cement used in the concrete mix, $20 \mathrm{lbs}$ of water is added. Water and cement are the two responsible ingredients for binding everything together in the concrete mix. There is a relationship between the strength of concrete and the $\mathrm{w} / \mathrm{c}$ of that concrete mix. When the mix design has a lower w/c, the strength of concrete would be higher. And that's because water addition would produce a diluted paste that is susceptible to cracking and shrinkage, which is the reason why the concrete would be considered weaker. When the fresh concrete that has a high w/c is placed, the weight of aggregate would let the excess water squeeze out. When there is a large amount of excess water, it would reach out to the surface. As a result, the small areas inside the concrete could allow water to flow, which would turn into micro-cracks. The amount of water used in the mix design of concrete is considered to be one of the most significant factors that could influence the properties of concrete (Neuwald, 2010). 


\subsection{Objectives and Scope}

The objectives of this research are to determine the water to cement ratio of concrete samples using the microwave method and determine whether this method is workable or not for both conventional concrete and SCC, and to compare the behavior between these two materials. One more objective of this research is to apply the ultrasonic pulse velocity method on concrete samples from both conventional concrete and SCC to determine the material's modulus of elasticity, and to analyze the results of the ultrasonic method using ABAQUS. 


\section{CHAPTER 2: Literature Review}

\subsection{Self Consolidating Concrete (SCC)}

\subsubsection{History of SCC}

In the late 1980's Japan introduced the idea of making the self-consolidating concrete as a better quality of concrete. After realizing that the regular concrete lacks some characteristics such as being stable and fully compacted which are needed to improve the performance of concrete structures. Full compaction of concrete on site was never considered a guaranteed idea, so as an alternative solution the focus turned onto developing a new kind of concrete, which doesn't require vibration in order for it to be compacted. That was the reason behind developing the first practicable SCC by the researchers at the University of Tokyo, and then the large Japanese contractors (e.g. Kajima, Maeda, Taisei etc.) immediately took this idea. The contractors used their facilities to create several SCC techniques. There several different mix designs and different test methods from these companies, (Civil Engineering , 2010), (Kazumasa OZAWA, 1992), (Hajime Okamura, 2003).

The development of a new generation of Superplasticizers (high-range water reducers), which are the Polycarboxylate helped transfer the idea of SCC to Europe in the 1990's. The technology has undergone a remarkable progress especially in Sweden, France, and UK. It was expected that the regular concrete would be placed with the new SCC in general construction areas in the UK. After a while, the SCC was also available in North America as a concrete mix offered by Lafarge and Lehigh and some cement manufacturers subsidiaries (Hurd, 2002). 


\subsubsection{Advantages and Limitations of SCC}

As mentioned earlier that SCC can reach full compaction without the need of vibration that explains the fact that $\mathrm{SCC}$ is a better alternative than the conventional concrete. When using SCC one can save time and effort by requiring less on-site workers, machinery, and energy that would lower the overall costs. One of the benefits is also improving health and safety by eliminating the usage of vibrators that would result in a less noisy working place that wouldn't require hearing protectors (Civil Engineering , 2010). The SCC provides a high level of quality control since the chemical admixtures are compatible and its ingredients are sensitive of the moisture content. It could provide a high quality finish particularly when dealing with architectural applications, cast in place constructions, and also precast constructions. It reduces the need of patching for surface defects and insures a better quality covering for the reinforcement bars. When using SCC the quality, durability and reliability of concrete structures could be improved since it's a better compacted and homogenous material. It is considered to be as an easy to place material especially when dealing with limited access elements. The byproduct materials such as: fly ash, quarry fines, and limestone dust would have a chance to be used when using the SCC (Tarun R. Naik, 2004). The formwork removal could be done easily and with less time for the SCC since it has a higher early strength compared to normal concrete. Other than the benefit of having the chance to save time and cost, implementation of SCC could also produce high quality structural members since it has low segregation, this would assure the perfection of performance.

Although there are many advantages of using SCC in construction, there are also many limitations resulted from the lack of knowledge and experience. The selection of material used to 
make the concrete could be more restricted compared with normal concrete. It also requires more accurate measurements and monitoring of the basic elements. Controlling the moisture content of the fine aggregate is important; it could affect the physical flow of the SCC even with only $1 \%$ change. It would require some time and effort since it requires more trial batches at both laboratories and concrete plants. As for the material cost, SCC is considered to be more costly compared to regular concrete.

\subsubsection{Developing SCC Mix Design Properties}

In order for the SCC mix design to be considered as an acceptable mix; it must meet three main characteristics given as follows:

1. Ability to flow into all areas of the formwork and fill complex forms under its own weight.

2. Ability to pass and flow through congested reinforcements such as: tight spaces between steel reinforcing bars, under its own weight.

3. The SCC must be able to resist segregation and remain uniform during transportation and placing. (Ouchi, 2003)

\subsubsection{Test Methods of SCC}

Many different methods have been introduced to characterize the SCC properties. No one yet has developed a method that could describe and introduce all those properties at once. Conventional workability methods designed for regular concrete mixtures are not sufficient for self-consolidating concrete, because they lack sensitivity while detecting segregates. Special test equipment and methods were designed to fit the criteria of SCC mixtures. Filling ability, passing ability, and resistance to segregation must be tested independently. A slump flow test could be 
used to test the filling ability, a j-ring test for the passing ability, and the penetration test for the segregation resistance ability. (Fowler, 2007)

Before sending any SCC batch to the jobsite, a check should be done before the start of every project. Workers must follow the guidelines that show the instructions in order to test the concrete whether at the production or the casting sites. ASTM provides several test methods to measure the SCC characteristics such as: ASTM C173 (Standard Test Method for Air Content of Freshly Mixed Concrete by the Volumetric Method) (ASTM, 2016). ASTM C1621 (Standard Test Method for Passing Ability of Self-Consolidating Concrete by J-Ring). Its performed in the same way of the slump flow test, but this particular test measures the difference in height of concrete inside and outside of the j-ring and should be done immediately after the slump cone is lifted (ASTM, 2014). ASTM C1712 (Standard Test Method for Rapid Assessment of Static Segregation Resistance of Self-Consolidating Concrete using penetration test). This test can be performed in the laboratory or before the placement of the mixture in the field (ASTM, 2014). Table 2.1 provides the requirements of site acceptance of SCC for prestressed concrete applications. 
Table 2.1 - Fresh properties requirements for site acceptance of Class S-P concrete (Chen et. al., 2012)

\begin{tabular}{|c|c|}
\hline Fresh Property & Acceptance Criteria \\
\hline Air Content (ASTM C173) & Target $\pm 2.0 \%$ \\
\hline Consistency (ASTM C1611) & Target Spread \pm 2.0 in. \\
\hline Passing Ability (ASTM C12621) & 2 seconds $\leq$ Measured $T 50 \leq 7$ seconds \\
& Visual Stability Index $\leq 1.0$ \\
\hline Rapid Segregation Resistance (ASTM & J-Ring Value $\leq 1.5$ in. \\
C1712) & Penetration Depth (PD) $\leq 0.5$ in. \\
\hline Unit Weight and Yield & \\
\hline
\end{tabular}

ASTM C1611 (Standard Test Method for Slump Flow of Self-Consolidating Concrete) This test can be done to observe the consistency of the SCC and its unlimited flow potential. It includes filling a slump cone then lifting the slump cone to measure the horizontal distance the concrete spreads (ASTM, 2014). According to ASTM C1611 the stability of SCC is ranked by VSI (visual stability index) from 0 to 3 as shown in Figure 2.1; (a) VSI $=0$, Concrete Mass is Homogeneous and No Evidence of Bleeding. (b) VSI = 1, Concrete Shows Slight Bleeding Observed as a Sheen on the Surface. (c) VSI = 2, Evidence of a Mortar Halo and Water Sheen. (d) VSI $=3$, Concentration of Coarse Aggregate at Center of Concrete Mass and Presence of a Mortar Halo 


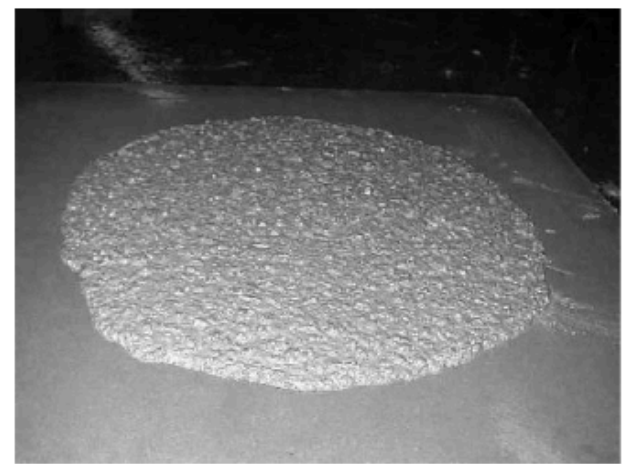

(a)

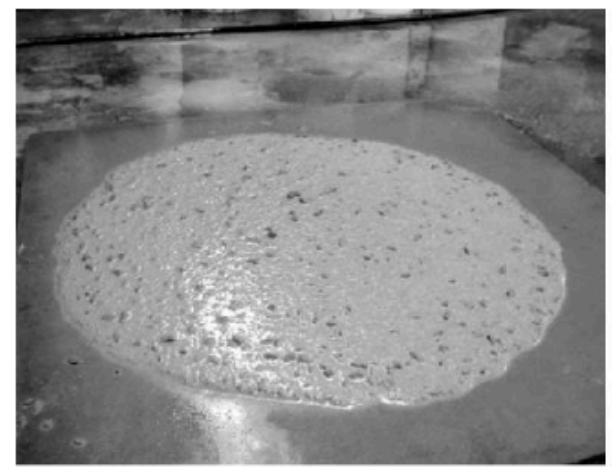

(c)

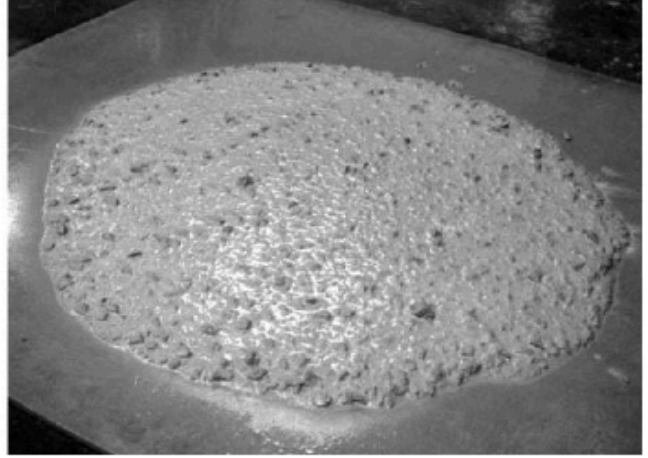

(b)

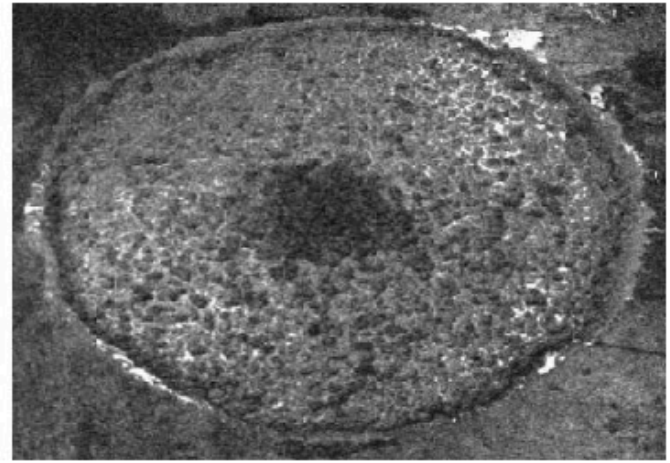

(d)

Figure 2.1 - VSI Criteria (ASTM, 2014)

\subsubsection{Materials and Mix Proportions}

Generally the SCC and the conventional concrete are both made using the same materials. There are many approaches that have been used to develop SCC. Increasing the amount of fine materials with keeping the water content same as conventional concrete could be considered as one method to obtain the self-compacting property. Another alternative way could be using a viscosity-modifying admixture (VMA), which could improve stability. In order to develop a mix with high deformability and sufficient workability that could result in having a good segregation resistance, VMA and an adequate amount of Superplasticizer (SP) must be 
used (Umar, 2011). The addition of more SPs to the conventional concrete wouldn't be enough to develop a SCC with the same workability. The passing ability could be improved by the usage of some filler materials.

The mix proportions procedures for SCC differ than those used for conventional concrete mix designs since its characterized by certain properties. The SCC mix can be developed using different methods, one is by using high powder content. Another method is by using viscositymodifying admixtures, or by combing both together (Manoj R. Vyawahare 1, 2015). The SCC mix can be obtained by following some guidelines such as: (1) Reducing the volume ratio of aggregate to cementitious material. (2) Increasing w/c and paste volume. (3) Control the total volume and the maximum coarse aggregate particle size. (4) Using different kinds of VMAs (Rajeev, 2012).

\section{Aggregates}

There are several shapes of aggregates that could be used to produce SCC such as: natural aggregate, rounded, semi-crushed, or crushed aggregates. The performance of the fresh and hardened concrete depends on the characteristics of the aggregates used in the mix. The volume of the paste that covers all particles is affected significantly by the shape and size of the coarse aggregate. Normally uncrushed gravel often requires less paste or mortar than limestone, but Granite would require more mortar volume. The interlinking of the angular particles in the crushed aggregates results in less flow, while rounded aggregates produce more flow due to less internal friction (O. R. KHALEEL 1a, 2011). 
The usage of a well-graded aggregate source could result in an economical SCC production. It is possible to use poorly graded aggregate in SCC mixes, but it would require more viscosity to prevent segregation. The passing ability could be affected by the size of the aggregate; a high maximum size requires a decreased coarse aggregate content. The amount of reinforcement bars and the gaps between them specifies the choice of maximum size of aggregate that would prevent aggregate blocking. Two parameters could ensure the best coarse aggregate content; maximum size of aggregate and the shape of the coarse aggregate. A high coarse aggregate content requires a lower maximum size. On the other hand, the possibility of using a high coarse aggregate content would increase with the use of rounded shape aggregates (Umar, 2011). Aggregates have an indirect influence on hardened properties; the mixture proportions that set the workability level can affect those properties more than the aggregates themselves. Aggregate characteristics can be described using packing density, which is affected by the geometrical properties such as: shape, angularity, texture, and grading.

\section{Chemical Admixtures}

The main chemical admixtures used to produce SCC are: high-range water reducing admixtures (HRWRAs) and viscosity-modifying admixture (VMAs). It is also possible to use air-entraining admixtures and set-modifying admixtures to produce a successful SCC mix. The polycarboxylate-based HRWRAs are considered as an improved kind of HRWRAs used to produce SCC, which has made the adoption of SCC much more easier than ever. The polycarboxylate-based HRWRAs have a lot of advantages compared to the sulfonate-based HRWRAs; they require fewer dosages, doesn't effect setting time as much as sulfonate-based HRWRAs, maintain high workability, and increase stability. What makes them different than 
each other is their structure and mode of action. The usage of polycarboxylate-based HRWRAs results in producing rheological characteristics that could improve the production of SCC (Jung, 2007).

The viscosity-modifying admixtures are used to increase many properties of the concrete mixture such as: yield stress, plastic viscosity, thixotropy, and shear thinning degree. They can be used to improve many properties of the SCC applications such as: resistance to segregation, increase cohesion, bleeding reduction, allow using wide-range materials such as gap-graded aggregates, and more importantly reduces the effect of variations in materials and proportions. They can be used as a substitute that could increase the powder content or reduce the water content in the concrete mixture. It is better to produce SCC mixtures without including VMAs if possible. When controlling the moisture content of an aggregate becomes a problem, it is necessary to use VMA. Another situation that would require using VMAs is when dealing with mixtures with poorly graded aggregates or minimum powder content (Jung, 2007).

In order to attain sufficient air content, air bubble size, air bubble spacing, and resistance to freeze-thaw the SCC mixture must contain air-entraining admixtures (AEAs). The change in the volume of air in the concrete depends on the change in the volume of paste for SCC, and both could effect the change in the percentage of air volume in the paste. Viscosity of the mixture can be reduced as a result of the entrained air bubbles that can affect the stability of the concrete and requires other solutions such as reduced water content. Researches have found that air void system in SCC can maintain its stability even after agitation. As a conclusion, segregation and 
loss of air would occur when yield stress and plastic viscosity are too low. In contrast the internal pressure of air bubbles would increase when they are too high (Jung, 2007).

\section{Cement}

One of the SCC mix design properties is that it includes more cementatious materials than conventional concrete and the reason behind that is to achieve desired flowability. The usage of cementatious materials may have some disadvantages such as: higher heat of hydration, higher cost, higher shrinkage ability. It is possible to use all standard types of Portland cements to produce SCC mixtures. Cement characteristics have a significant influence in the performance of the admixture (Jung, 2007).

\section{Supplementary Cementitious Materials}

Nowadays supplementary cementitious materials (SCMs) are used in most of the highperformance concrete mixtures as they have a lot of advantages. The performance of the concrete could be highly improved by the usage of SCMs; decrease cost, enhance workability, reduce heat of hydration, and improve durability. There are many kinds of SCMs that can be used in concrete mixes but the most common ones are: fly ash, silica fume, and slag cement (Supplementary cementitious materials, 2009). Researchers have discovered that the replacement of cement by class F fly ash resulted in improving workability of the concrete, but it would lower its compressive strength at early ages. Using the class F fly ash as a major constituent of concrete mixes has several advantages such as: reduce the need of super-plasticizer (SP), increase the chloride permeability resistance, and increase workability. Following this further, the mechanical properties and the durability of the concrete mixture are highly affected by the usage of silica 
fume and slag. SCC mix designs with a combination of fly ash, slag, cement, and VMA could result in an economical mixture with required properties (Enad Mahmoud, 2013).

\subsubsection{Placing, Transferring, and Curing of SCC}

Although SCC has an advantage when it doesn't require a lot of time for placing, but it is important to balance the plant production capacity, placing capability, and transportation duration so that the concrete could be placed within the desired time and without any shortage in supply. Lift lines could occur on the vertical surface of the concrete and the filling ability could be affected due to continuous stops during production time (Specification, Production and Use, 2005).

There are many different methods that could be used to transfer SCC such as: mixer trucks, sidewinders, pumping, clam buckets, overhead cranes, and forklifts. Each method should be done in a way that ensures a satisfying job by not causing segregation. Sufficient amount of SCC should be available when casting the mold to decrease the chance of having cold joints, pour lines, and prevent segregation. Mixer trucks are considered to be one of the most useful methods used to deliver SCC especially when used in rough areas and for long distances (Curtis Badman, 2003). The time needed for discharging the concrete at the jobsite could be shortened if there was a close connection between the concrete producer and the contractor. The concrete producer's technicians or any consultant familiar with the concrete performance are responsible of any additional necessary adjustments. Preventing delays is highly required in placing and delivering to ensure the quality control of the concrete. 
Curing concrete means protecting its moisture content and controlling its temperature range. There are many advantages of curing the concrete such as: increases strength of concrete, increases abrasion resistance, reduces the chance of concrete scaling, prevents cracking, and reduces the chance of surface dusting. Curing is an essential step in all concrete constructions, but it is considered to be more important when it's done for the top surface of SCC. The low water/fines ratio and high amount of paste in SCC makes it an easy target for surface drying which could lead to shrinkage cracks as a result of losing moisture at early ages. Curing should be done as soon as practically possible. Fog misting and evaporation retardants are very useful to prevent surface curing problems (Ontario, 2009).

\subsubsection{Mechanical Properties of SCC}

The study of the properties of hardened concrete is important and provides a better understanding of whether structural members made with SCC could be calculated with the same design rules of the regular concrete. The hardened properties are useful for the design and quality control of concrete. There are many different mechanical properties that should be tested for SCC such as: compressive strength, tensile strength, modulus of elasticity, shrinkage, creep, coefficient of thermal expansion, bond to reinforcement, shear force capacity in cold joints, and fire resistance. (Specification, Production and Use, 2005)

\section{Compressive Strength}

The compressive strength is considered to be the most important compared to all other mechanical properties. There are several factors that could affect the compressive strength of 
concrete such as: specimen size, load rate, and curing conditions. The ASTM C39M - 11 "Standard Test Method for Compressive Strength of Cylindrical Concrete Specimens." was developed to control differences in testing and results. This test method is used for molded cylinders and drilled cores and is limited to no more than $800 \mathrm{~kg} / \mathrm{m}^{3}\left[50 \mathrm{lb} / \mathrm{ft}^{3}\right]$ density of concrete (ASTM, 2011). The SCC and the normally vibrated concrete have almost the same rate of gain of compressive strength when they are made with the same amount of cement and water/cement ratio is the same, but they would vary when using limestone-type additions. Researchers have found that the compressive strength increases significantly for all ages of the concrete up to 28 days (technology, 2012).

\section{Tensile Strength}

Any class of compressive strength could be used for SCC; the tensile strength could easily be the same as the one used for conventional concrete since it wouldn't be highly affected by the volume paste of the concrete. The bending tensile strength of concrete has many significant uses during the design of reinforced concrete sections. It could be used to estimate cracking moment in prestressed sections. Thermal contraction at early ages could cause width cracking and spacing, which could be controlled by the bending tensile strength (Specification, Production and Use, 2005).

The tensile strength of SCC is evaluated by the splitting test on cylinders. This test is defined in ASTM C 496-11, "Standard Test Method for Splitting Tensile Strength of Cylindrical Concrete Specimens" (ASTM, 2004). Researches have found that hardened SCC has a tensile strength same or even better than conventional concrete. As compared to normally vibrated 
concrete, some considerable differences were obtained for the values of SCC as they were up to 40\% higher (Marian Sab, 2012).

The efficiency of the compaction and curing of the concrete in a structure influences the strength of the concrete. Some researchers have studied the correlation between the tensile strength and aggregates and their influences on the concrete performance. They have showed that tensile strength is affected by several factors such as: bond strength between cement paste and aggregate, resistance of crack, and shear. Other researchers have shown that tensile strength could be higher than normal concrete when using high-strength concrete (f'c $>50 \mathrm{MPa}$ ) in penetration-resistant structures, which was a result of the usage of high-range water reducers, adding silica fume, and different curing conditions (Druta, 2003).

\section{Modulus of Elasticity}

The modulus of elasticity (E-value) is traditionally defined as the relationship between stress and strain. The modulus of elasticity could be useful in different aspects such as: calculating deflection, works as a controlling parameter in slab design, and of pre or posttensioned sections. The relationship between the modulus of elasticity and compressive strength could be influenced by two important variables such as: the aggregate characteristics and the different mineral admixtures. The E-value, type, and the amount of aggregate used in concrete have the most significant impact on its performance since aggregates constitute the largest percentage of the volume of concrete. There is a proportional relationship between the E-value of aggregate and the E-value of concrete; the usage of an aggregate with high E-value results in high modulus of elasticity of concrete. On the other hand the relationship between the E-value 
and the volume of the paste is inverse. As compared to the E-value of conventional concrete, SCC has a lower value due to the high paste content. The maximum aggregate size could also affect the E-value of concrete; it would be higher when using $20 \mathrm{~mm}$ (3/4 in) maximum aggregate size than using $16 \mathrm{~mm}$ (5/8 in) maximum aggregate size. It has been found that for a given compressive strength, using mineral admixtures results in an increment in the value of the modulus of elasticity of the mixture. Each type of the different mineral admixture used has a different impact on increasing the E-value of the mixture; it increases based on the following order of the different types: fly ash, limestone filler, and lastly ground-granulated blast-furnace slag (GGBFS) (Specification, Production and Use, 2005) (Angel Vilanova, 2012).

When concrete is subjected to uni-axial load, the ratio of the axial stress to the axial strain of that material would be considered as the static Young's modulus (E). It is important for structural engineers to know the value of E since it is usable in the design process. The dynamic Young's modulus can be determined using the non-destructive dynamic methods. But the obtained dynamic Young's modulus wouldn't be usually accurate since it differs than the static one; it usually has a higher value. It is known that $E_{d}$ values for a given concrete specimen determined using different dynamic methods would differ from each other (Philleo 1955). In general, $E_{d}$ values obtained from ultrasonic pulse velocity test using wave propagation are known to be higher than those determined using other vibration methods for the same concrete specimen (Popovics, 2008). The methods for the determination of dynamic Young's modulus have many advantages over those for static methods; better accuracy, shapes and sizes of samples can vary, tests can be done under different temperatures, and more importantly the methods are nondestructive and thus tests can be repeated on the same sample. 


\section{Creep and Shrinkage}

The increase in deformation of the concrete elements resulted from the constant applied load is known as creep. The controlling factors of the properties of creep in conventional concrete are similar to those for SCC, which are: the mix water content, amount of cement used, and aggregates nature. The porosity of the cement paste of the mix and the type of cement affects creep since it occurs in there. As the strength of concrete increases creep reduces, due to the reduction of the porosity of cement paste during hydration. Researchers have found that when the water/cement ratio of the mix decreases, creep decreases as well. On the other hand an increase in the cement/powder ratio of the mix results in a decrease in creep if the amount of water remains the same. As for the type of cement used, the faster the cement hydrates the higher the strength is, which leads to lower creep with lower stress/strength ratio. As compared to conventional concrete, SCC could have a higher creep coefficient since its cement paste volume is higher when both have the same strength (Specification, Production and Use, 2005) (Marian Sab, 2012). The results of a study that was done by Krit (Kangvanpanich, 2002) about the early age creep of SCC show that creep of unsealed SCC was 1.4 times greater than normal concrete. And the creep of sealed SCC was 1.1 times greater than normal concrete.

There are two kinds of shrinkage in concrete: autogenous and drying shrinkage. During hydration internal water consumption might occur which could be the reason behind the autodegous shrinkage that takes place during setting. Tensile stresses are the result of the fact that the volume of the cement and water before hydrating is higher than the volume of hydrated products, which explains the occurrence of autogenous shrinkage. As regards to drying shrinkage 
it is resulted when concrete loses its water to the atmosphere, which could be from the aggregates or the cement paste. Researchers have proven that shrinkage in SCC is directly proportional to the paste proportioning. The volume of the paste could be considered as an essential parameter that influences the shrinkage in SCC. The probability of having drying shrinkage decreases as the volume of aggregate increases since it prevents the shrinkage of cement paste. The maximum aggregate size also affects the drying shrinkage; when the size decreases the shrinkage increases due to its relationship with the paste volume (Specification, Production and Use, 2005) (Nasr-Eddine Bouhamou, 2013).

\section{Bond to Reinforcement}

The load bearing capacity of a reinforced concrete structures is significantly dependent on the performance of the bond between the reinforcing bars and the concrete. Adequate concrete bond strength has the ability to prevent failures in concrete structures. Based on many studies that have been done regarding the behavior of rebars in concrete, it have been proven that there are several factors that could affect that behavior such as: the rebars surface, the mix design, the number of load cycles, the direction of casting the concrete, and the specimen's geometry. As compared to the conventional concrete the bond strength in SCC is greater due to its high fluidity and better filling ability (F. M. ALMEIDA FILHO, 2008) (Weibe, 2000).

\subsection{Water to Cement Ratio of Concrete (w/c)}




\subsubsection{Effects of water addition to concrete}

Water can be added to ready mixed concrete using a truck mixer when it arrives to the jobsite. The water used for addition could be from the unused or the surplus of the design mixing water during initial mixing which must be controlled regarding the purchaser's need. The addition of water could be done to assure that the slump of concrete meets the specifications of the mix design. According to ASTM C94, "Standard Specification for Ready-Mixed Concrete" the slump and water to cement ratio of concrete must not be exceeded to ensure desired performance and workability of concrete (ASTM, 2016). The addition of water is associated with the characteristics of concrete; strength and cracking ability could be significantly affected by adding water as shown in Figure 2.2. It is possible to use water-reducing admixtures or superplacticizers instead of adding water to increase the slump of concrete, which could at the same time insure that the concrete properties remain the same (About concrete, 1995).

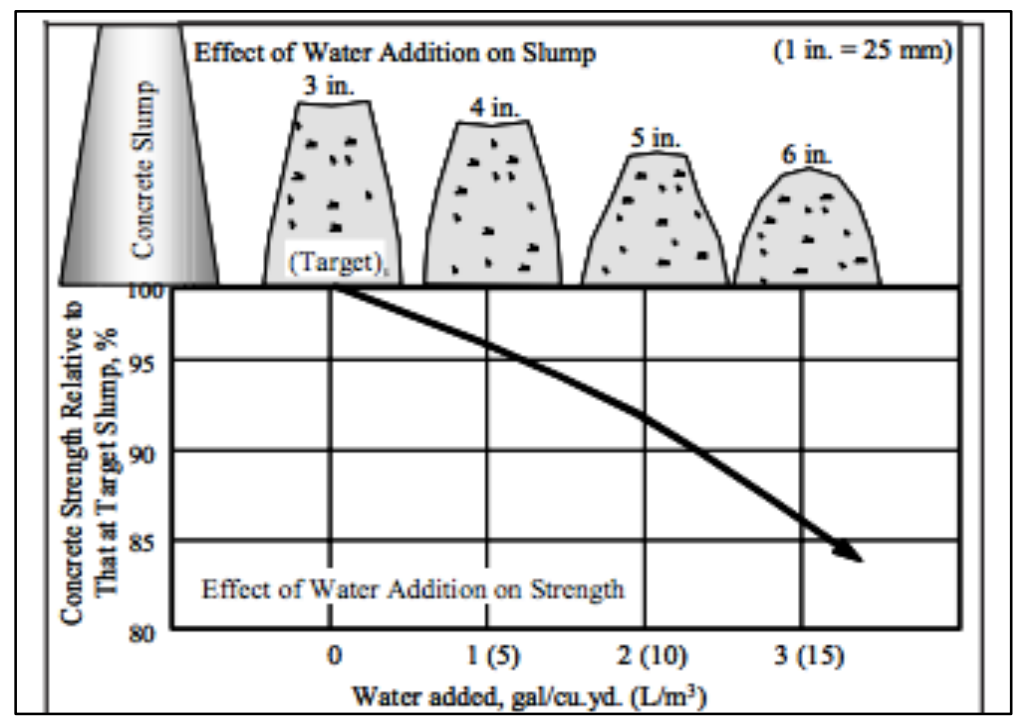

Figure 2.2 - Effect of water addition to the compressive strength. (About concrete, 1995) 
The fact that water to cement ratio influences the workability of fresh concrete and the strength of hardened concrete was a well-known engineering concept ever since concrete was first used. Duff Abrams, an American researcher in the field of composition and properties of concrete, was the first to discover the relationship between w/c and strength in concrete in 1918, which was known as Abram's Law. The relationship is explained in Eq. (1) as follows:

$$
f^{\prime} c=\frac{A}{B^{w / c}}
$$

Where $f^{\prime} c$ represents the compressive strength of concrete, and $A$ and $B$ are experimental constants that show the effects of type of aggregate and cement used, curing and testing conditions, and age of concrete at time of test (K.S. Pann, 2003).

The w/c of concrete must be controlled otherwise many negative outcomes could result. The inability to achieve desired compressive strength of concrete. The resulted high permeability could lead to less durability of concrete, which would highly affect its fresh properties. The workability, durability, strength and cost must all be taken under consideration during the design of a concrete mix. The consistency of concrete that is dependent of the slump of the mix, and the cohesiveness are the factors that affect workability. As for durability of concrete, it is influenced by the w/c of concrete and the permeability since it's related to porosity.

The determination of how much water could be added to concrete is important to ensure a good quality and performance. According to the general rule of thumb that water can be added to certain limit where it could regulate the slump of the material and meet the specifications so that $\mathrm{w} / \mathrm{c}$ of concrete is not exceeded. It states that one gallon of water added increases the slump of one yard of concrete by 1 inch. Temperature and air content should be also taken under 
consideration due to their effect on the amount of water needed to increase slump of concrete (Turici, 2013). As stated in ASTM C94 that adding water cannot be done after any significant discharge of concrete from the mixer, since neither the amount of concrete nor the impact of water added on the characteristics of concrete would be known. The slump and air content of concrete can be measured from a sample of the initial portion of the discharge according to ASTM C94 so that any improvements in the slump or air content could be done to the whole amount of concrete (ASTM, 2016).

\subsubsection{Controlling Water Content of SCC}

Controlling the water content in production is more important when dealing with SCC than the conventional concrete. The effects of the change in water content are measured in terms of fresh properties, durability, and strength. The source of those changes varies depending on the several parts of the process of concrete production and each has different effects. One source could be the change in water content in aggregates, which is considered as one of the most significant ones. Storing and transportation systems could be considered as another source; rainfalls and evaporations could result in an increase or decrease in the water content (Controlling water in self compacting concrete production, 2010).

The performance of the concrete can be affected by the change in water content in different ways. It would affect the dry aggregate weight significantly; for every $1000 \mathrm{~kg}$ of dry aggregate weight a $10 \mathrm{~kg}$ change of aggregate placed into the mixer would result if a change of $1 \%$ moisture content happens. There is a positive relationship between the change in moisture and the change in the weight of aggregate; the greater the change in moisture, the greater the weight 
of aggregate needed. It is shown from Table 2.2 below that the finer the aggregate is, the more the range of the moisture content increases. The reason behind that is the increased aggregate surface area by weight. The SCC uses about $48-55 \%$ fine aggregates of the total aggregate weight, which is considered to be high in comparison to the conventional concrete, which increases the possibility of being affected by the change in moisture content (Controlling water in self compacting concrete production, 2010).

\section{Table 2.2 - Typical moisture ranges for concrete aggregates (Controlling water in self compacting concrete production, 2010).}

\begin{tabular}{|l|l|}
\hline Size & Moisture \% Range \\
\hline Fine Sand & 0 to 16 \\
\hline Coarse Sand & 0 to 12 \\
\hline $8 \mathrm{~mm}$ & 0 to 10 \\
\hline $10 \mathrm{~mm}$ & 0 to 4 \\
\hline $12 \mathrm{~mm}$ & 0 to 3 \\
\hline $20 \mathrm{~mm}$ & 0 to 2 \\
\hline
\end{tabular}

The volume of the water distributed into the concrete mixer is also affected by the variation of water content. Significant effects on the workability of the SCC will be taken under consideration when a change of 24 liters of water occurs as a result of $1 \%$ change in water content. Any changes in the water content could affect the strength of the concrete since the compressive and tensile strengths of concrete are highly dependent upon its water/cement ratio. The w/c ratio and creep are related to each other, so the durability of the concrete could be affected by the change in moisture too. It is possible to face shrinkage during hydration due to the change in water content since it is related to the internal water consumption. There are direct and indirect effects of moisture variation that could also reach the flowability of the SCC. The flowability properties of the concrete are related to the aggregate grading which could be 
affected by the change in water content as mentioned earlier. The interactions between the changes in dry aggregate grading and aggregate surface area with the usage of high-range water reducers could also be considered to cause an indirect effect. One way to avoid and lessen those effects is to use the viscosity modifying agents (Controlling water in self compacting concrete production, 2010).

\subsubsection{Methods to Determine w/c}

Rapid determination of the composition and potential strength of fresh concrete is becoming very important in the area of modern construction technology nowadays. An ideal time for testing fresh concrete properties would be prior to placing it in the forms after casting. Knowing whether the concrete qualifies the job specifications or not is related to the determination of $\mathrm{w} / \mathrm{c}$ ratio at an early point. There are several factors that specify whether a method could be considered ideal or not such as: accuracy (95\% confidence level), fast (takes less than 15 minutes), easy to perform, inexpensive, applicable in the field, and independent on components type. (Ramme, 1989) The determination of w/c ratio is one of the main factors in testing the quality of fresh concrete and is considered one of the hardest parameters to measure (R, 1987).

\section{The Buoyancy Method}

This method explains how the rapid determination of water to cement ratio of fresh concrete could be done rapidly using the buoyancy principle of Archimedes (Robert Resnick, 1970): "A body wholly or partly immersed in a fluid is buoyed up with a force equal to the 
weight of the fluid displaced by the body." based on the experiment done by Naik and Ramme, the specific gravity of cement, aggregates, and aggregate to cement ratio must be measured before performing the test to be able to calculate the water to cement ratio. While performing the test the cement weight ratio and SSD (saturated surface dry) aggregates can be also determined. They have performed 8 different tests and the results were reasonably accurate with a 4.1 average percent error (Ramme, 1989).

The experiment was performed by preparing a container filled with $22 \mathrm{lb}$ concrete and 0.2 in water. Entrapped air is removed by stirring the concrete and water. Then the container is filled with water and is removed by sliding the stirrer across the surface. Next the overflow water is removed from the container to be able to get the underwater weight of concrete. Finally the water to cement ratio could be measured using the obtained values. This method could be considered effective in a way as it enables a rapid determination of the w/c ratio. On the other

hand when considering the minor changes in the materials used in concrete, results could significantly be affected. And when applying such method with concrete containing cementitious material, it would result in losing some of those materials based on the way this experiment works. (Ramme, 1989)

\section{James Cementometer Method}

The James Cementometer is one of the devices used to determine w/c ratio of wet cement and concrete. This device has several benefits such as: simple and fast to use, provides accurate results, completely portable, and it provides full range of w/c ratio's immediate readings. The dielectric constant of the material that is being tested could be measured using two prong sensors 
connected to the material. The changes in water content have a significant influence on the sensor results since the dielectric constant of water is 4 to 8 times greater than most aggregates and cements. Several reading must be taken in order to get a valid one, and then integrated microprocessor should be used to convert the result and get the moisture content. There are two different types of Cementometers for different w/c ratio ranges; Type $\mathrm{R}$ deals with normal w/c ratios ranging from 0.35 to 0.65 and the Type $\mathrm{L}$ deals with low $\mathrm{w} / \mathrm{c}$ ratios ranging from 0.25 to 0.5. The device's settings are designed to handle type I, II, and III cements. More than that the device can store more than 150 readings with time and date. The full unit of the device would cost approximately $\$ 2,000$ (James Cementometer).

The Cementometer was used by some reasearches such as Peterson and Sutter in their studies regarding the determination of $\mathrm{w} / \mathrm{c}$ ratio. The device has a lot of advantages as mentioned earlier but they have found from their experiment that w/c ratio results were not accurate in a quality control manner. Their study tested both factory and user calibrated setting to determine the w/c ratio. They have concluded that the different types of chemical used in concrete (SCC type of concrete) influences the performance of the device; affects the dielectric constant of concrete, which is an important key in determining the w/c ratio (Peterson, 2011).

\section{Gravitational Analysis using Microwave Method}

This method is going to be applied in this research for both conventional concrete and SCC to determine the $\mathrm{w} / \mathrm{c}$ ratio of freshly mixed concrete. The experiment can be done using a microwave of a 900 watt power or more to dry the concrete samples for several time intervals. The weight of concrete sample must be recorded after each time interval until the change in 
weight is less than or equal to 1 gram. The standard provides the procedure that could be used to calculate the water content. (Hershberger, 2015) The experiment has showed many successful results when studied by several researchers. Peterson and Sutter have studied this method and described it as a promising method for on-site w/c ratio determination and gives accurate results. Many researches have been done using this method to test regular concrete mixes but few were done on SCC.

Previous studies have showed that the moisture content, percent absorption values, and specific gravities could be measured by drying aggregates rapidly using the microwave oven method. (Ramme, 1989) During this method, the mass loss would be known as the evaporable water when assuming all water was removed by the microwave. The difference in mass between initial fresh concrete and dried one was represented as water content of sample, the w/c could be measured then using the mix design's cement content. The first eight concrete mixes Naik and Ramme tested using this method were $100 \%$ Portland cement with w/c raging from $0.36-0.73$ and the results varies with an error of $+28 \%$ to $-11 \%$ (Ramme, 1987). Following this further, a research was done Jonathan Rebelo to evaluate the test methods for determining the w/c of fresh and hardened concrete. He concluded that not obtaining a representative sample when applying this method was considered as the number one source of error. It was also concluded that an aggregate correction factor must be taken under consideration when testing concrete using the microwave method (Rebelo, 2014). Jared Hershberger did a research on the determination of w/c of SCC and conventional concrete using the microwave method. It was concluded that implementing a correction factor or a modification to the experimental method may provide more accurate results (Hershberger, 2015). 


\subsection{Ultrasonic Testing}

\subsubsection{Fundamental Principle of UPV Method}

It is important to distinguish and study the properties of the materials used in a structure to extend its lifetime. NDT tests can be used as a strategy that could be followed to evaluate the conditions, estimate the quality, and determine the strength of concrete. The ultrasonic pulse velocity method is used in structural engineering to determine material properties such as the strength of concrete. The method can also be used to check uniformity of concrete, detect cracking and voids in concrete, control the quality of concrete and its products (by comparing results to similar concrete), detect deterioration and condition of concrete, and to detect the depth of a surface crack. The characteristics of wave propagation that are used to determine those properties are: velocity, attenuation, frequency, and energy (Ismail Ozgur Yaman, 2001).

During the Ultrasonic test the concrete sample that is being tested will be in contact with an electro-acoustical transducer from one side, which will produce a pulse of three distinct types of elastic wave propagation. The fastest of these waves is known as the longitudinal compression or P-wave and is know for its particle displacements that travel in the same direction as the disturbance. Second are the surface waves, which are known to be the slowest and have an elliptical particle displacement. Finally the shear or transverse waves that have particle displacement at right angles to the travel direction and are faster than surface waves. The wave velocity depends on the mass and the elastic properties of the material. The determination of the elastic properties of the material becomes easy when the mass and velocity of wave propagation are known (I. Lawson, 2011). The compression wave velocity for infinite, isotropic elastic, 
homogeneous material can be determined according to the "The European Classification of Exposure Environmental for Concrete" using the following equation:

$V_{p}=\sqrt{\frac{E(1-v)}{\rho(1+v)(1-2 v)}}$

Where $V_{p}=$ Compressive wave velocity $(\mathrm{km} / \mathrm{s}), E=$ the dynamic Young's modulus of elasticity $\left(\mathrm{kN} / \mathrm{mm}^{2}\right), v=$ dynamic Poisson's ratio, and $\rho=$ mass density $\left(\mathrm{kg} / \mathrm{m}^{3}\right)$.

While performing the contact testing applications ultrasonic couplants are usually used to help the transmission of the sound energy between the transducer and the tested sample. Couplants will usually be viscous, nontoxic liquids, gels, or pastes. The usage of these couplants has many benefits and could really improve the results of the test. It is important to use them because the sound energy at the ultrasonic frequencies used in nondestructive testing is not transmitted through the air in an effective way. Any air gap between the transduced and the sample that is being tested even if it was a really thin one will result in an inefficient sound energy transmission. It is basically impossible for the conventional testing to happen when there is an air gap between the sample and the transducer. There are many alternatives that can be used in different applications as ultrasonic couplants such as: water, motor oil, grease, and hair gel. But when performing high temperature testing, the specially formulated couplants are more recommended for better results. Moreover testing in nuclear industry requires a special kind of couplants; couplants with limited halogen and sulfur (Ultrasonic Couplants). 


\subsubsection{Factors Affecting UPV Test}

Despite the fact that the ultrasonic testing is an important method that helps determine the properties of concrete, the results could be influenced by several factors. Those factors could be categorized into two different types, the ones caused by the concrete behavior or those associated with the technical errors such as human errors.

\section{Size and Type of Aggregate}

Many researches have found that there is a significant relationship between the size and type of aggregate and the UPV results, which would influence the concrete properties. According to the studies done by Jones, Trtnik, Kavcic and Turk the concrete that has a higher aggregate content would have a higher pulse velocity when strength of concrete is fixed (Jones R. , 1962) (Trtnik G., 2009). Following this further, Berriman, Purnell, Hutchins and Neild have found that the concrete aggregate content could highly affect the speed of sound (Berriman, 2005). But it should be taken under consideration that it's right that the strength of concrete and UPV result are affected by the concrete aggregate content but not to the same extent; the UPV results are more influenced by the vibrations of the aggregate size and type than the strength (Trtnik G., 2009). Some studies have showed the relationship between the aggregate type and the UPV results; when comparing three samples that have same mixture and compressive strength it would show that the highest pulse velocity would result from the concrete with crushed limestone, then crushed granite would have an intermediate velocity, and finally the rounded gravel would give the lowest value (Jones R. , 1954). 


\section{Water to Cement Ratio (w/c)}

The effect of the moisture content in concrete is important for the determination of the strength of concrete. There is a study done by Ye, Lura, Van Breugel, and Fraaij where they used three concrete samples with different w/c ratios $(0.4,0.45$, and 0.55$)$, the result of the study showed that as the w/c ratio gets lower the values of the UPV test gets higher as shown in Figure 2.3, which might be related to the higher amount of solids in the mixes. Samples that have lower w/c ratio would contain higher amount of aggregate and that would result in an increase in UPV values (Ye, 2004).

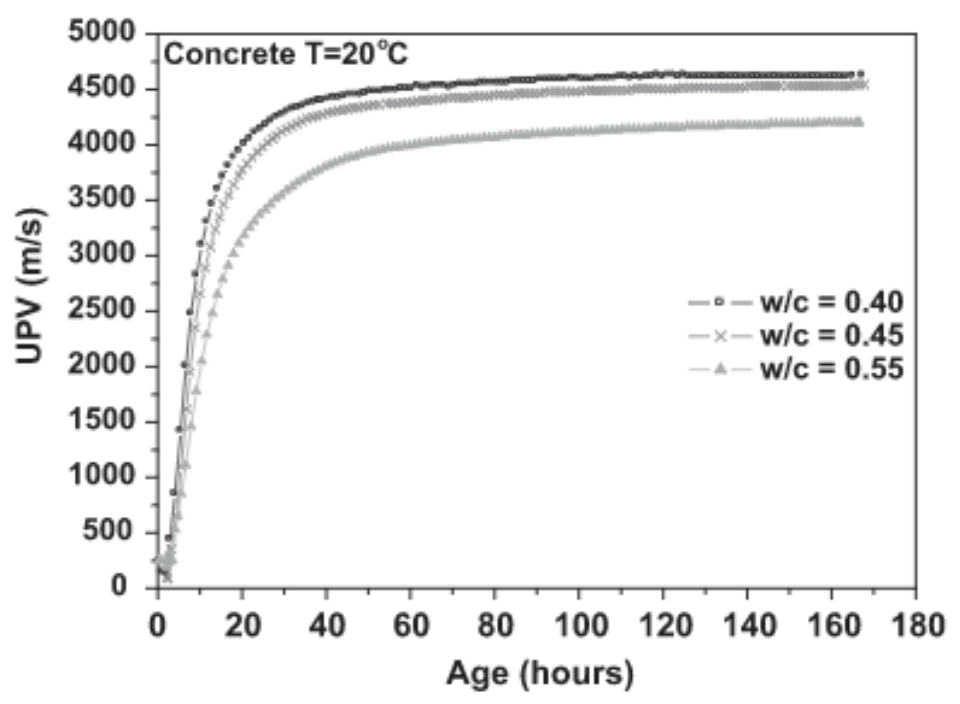

Figure 2.3 - effects of w/c on UPV results (Ye, 2004).

Kaplan who also studied the relationship between UPA values and w/c ratio of the concrete also concluded that there is a negative relationship between $\mathrm{w} / \mathrm{c}$ and the strength of concrete and UPV test results. He have also proven that at later ages of curing when the volume of pores is less, the effect of w/c on the pulse velocity would be more clear (Kaplan, 1959). 


\section{Admixture}

Silica fume (SF) and fly ash (FA) are some of the effective admixtures that could be used in concrete. The density of concrete could be improved due to the pozzolanic reaction caused by silica fume. They are effective as they could reduce permeability as a result of their ability to fill in voids. Fly ash admixtures could be used to fill micro-voids between cement particles in selfconsolidating concrete (Gebretsadik B. T., 2013). The effect of using silica fume and fly ash instead of Portland cement (PC) on UPV results in self-consolidating concrete was studied by Ulucan, Türk and Karata. They have concluded that as FA replacement of PC increases the UPV values would decrease for the SCC at 3 and 7 days. They've also found that UPV results would be the highest at 28 and 130 days of curing when SCC contains 30\% fly ash (Ulucan Z. Ç., 2008).

\section{Concrete Age}

As the curing age of concrete increases the void spaces would decrease which is the reason why the concrete would be stronger. As the gel/space ratio (which is affected by time) increases the volume of pores decreases and the wave propagation increases due to the fact that pulse velocity in voids is less than solids and liquids. (Ikpong A.A., 1993) Studies have showed that at an early age the pulse velocity increases rapidly and then it gets smoother (Jones R. , 1954). 


\section{Volume of Steel Fibers}

The density of the concrete would increase as a result of adding steel fibers since it has a high specific gravity, 7.84. Based on the wave propagation theory, an increase in the material density would result in a decrease in the wave velocity in it, which would lead to lower UPV values influenced by the high density steel fibers used. There are some studies done by AlOwaisy show that high volumes of steel fibers might result in a decrease in the UPV results. And that's due to the appearance of voids and non-homogeneity in Steel Fiber Reinforced Concrete (SFRC), which affects the UPV significantly (Al-Owaisy, 2006).

\section{Other Factors:}

There are many other factors that could affect the UPV test results and must be taken under consideration such as: temperature, moisture condition, surface roughness, varying pressure on transducers, and porosity. According to Malhotra and Carino the surface roughness and porosity are known to cause the most significant effects. They have also reported that the large differences in temperature $\left(\geq 30^{\circ}\right)$ affected the test values. According to their results, the UPV values increased with the moisture content and decreased with increasing porosity, temperature, and air pockets between transducers interfaces (Malhotra, 2004).

\subsubsection{Methods of Testing UPV}

There are three main ways in which the transducers can be arranged, and those will determine a different method of testing as shown in Figure 2.4. The first method is called direct transmission where the transducers will be placed opposite to each other on the faces of the 
concrete sample. Second method is called the semi-direct transmission where the transducers will be placed adjacently on the faces of the concrete sample. The last method is called the indirect transmission where the transducers will be placed on the same face of the concrete sample (Kaouther, 2014).

The direct transmission method is considered to be the most accurate and trusted one, that's because the transmission of the maximum pulse energy is measured at right angles to the face of transmitter. Regarding the determination of the quality of concrete, using the direct method would be the best option since it provides a well-defined path that could be measured easily (Malhotra, 2004).

As for the semi-direct method the results would sometimes be satisfying that's only when the angle between the two transducers is not too large, and the length of the path is not too large. When performing this method it is important to qualify the previous requirements in order to get the best results. Otherwise there would be a big chance that the signals will not be clear because of the attenuation of the transmitted pulse. The length of the path in this method is not clearly defined as the direct transmission method that's because the size of the transducer is limited. It would be sufficient to measure the length of the path from center to center of transducer faces (Malhotra, 2004).

Out of the three testing methods, the indirect method is known to have the least satisfying results, and that's because the amplitude of the received signal could be less than $3 \%$ compared to a received signal of a direct transmission. The receiving signal is highly exposed to errors since it depends mostly on the propagation of the pulse (Malhotra, 2004). 

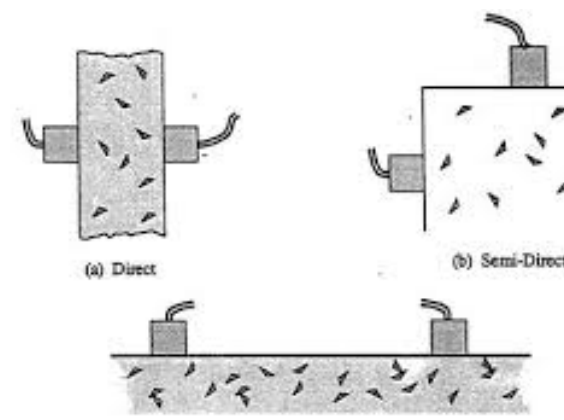

(c) indirect

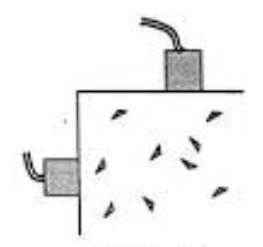

Semi-Dirost

Figure 2.4 - (a) direct, (b) Semi-direct, (c) Indirect (Kaouther, 2014).

\subsubsection{Advantages and Limitations}

The ultrasonic pulse velocity test is one of the most important non-destructive methods used to determine the uniformity of concrete. The test procedure is simple and the equipment used is available in the market and easy to use. The ultrasonic pulse velocity test can be applied on both small specimens at the laboratory or large concrete structures at the filed. The devices used in this test have a high penetrating power, which provides a deep detection of flaws in tested samples. They are also very sensitive in a way that allows the detection of extremely small flaws. The test does not require more than two surfaces that should be accessible in order to be done. The ultrasonic pulse velocity method has more accuracy in determining how deep are the internal flaws compared with the other non-destructive methods. More than that UPV test is capable of determining the size, shape, and nature of defects (Malhotra, 2004).

Some inspection procedures are required for this non-destructive testing method. Before performing the test, users must make sure that both transducers are connected with the right wires. It is difficult to test samples that are rough, irregular in shape, very thin, or not 
homogenous. More than that, the surface of the sample needs to be clean before performing the test otherwise anything that is on the surface would affect the results. Moreover the tested samples must be water resistant and the usage of couplants is needed for better reading and results (Malhotra, 2004) (Gebretsadik B. T., 2013). 


\section{CHAPTER 3: Experiments and Results}

\subsection{Casting and Mix Design}

For the purpose of this study, two different concrete castings were held at West Virginia University's concrete lab, one was for the conventional concrete and the other one was for the SCC. The materials used for the castings were obtained from Central Supply Company. Additionally, the chemical admixtures required for conventional concrete and SCC castings were from Euclid Chemical and BASF, respectively. The moisture content of aggregates used in the mix was determined based on ASTM C566 - Standard Test Method for Total Evaporable Moisture Content of Aggregate by Drying (ASTM, 2013).

$P=\frac{100(W-D)}{D}$

Where:

$\mathrm{P}=$ moisture content of sample, $\%$

$\mathrm{W}=$ original wet mass of sample

$\mathrm{D}=$ dry mass of sample

The moisture content of large aggregate from the casting of fly ash mix concrete was determined to be approximately $0.669 \%$ and the moisture content of fine aggregate was determined to be $4.697 \%$. With SDD equals to $1.9 \%$ of fine aggregate and $0.5 \%$ large aggregate, the extra moisture contents were approximately equal to $2.794 \%$ for fine aggregate, and $0.169 \%$ for large aggregate. The w/cm ratio was approximately 0.402 in this concrete mix. As for the SCC casting, the moisture content of large aggregate was determined to be approximately $2.365 \%$ and the moisture content of fine aggregate was determined to be $8.558 \%$. With SDD equals to $1.9 \%$ for fine aggregate and $0.5 \%$ for large aggregate, the extra moisture contents were 
approximately equal to $6.658 \%$ for fine aggregate and $1.865 \%$ for large aggregate. The $\mathrm{w} / \mathrm{cm}$ ratio of the SCC mix was approximately 0.342 .

Both SCC and regular concrete were casted using the laboratory drum mixer based on the ASTM C192 - Standard Practice for Making and Curing Concrete Test Specimens in the Laboratory (ASTM, 2016). Total of $1.8-\mathrm{ft}^{3}$ regular concrete was produced during the first casting. During this casting three 3"x4"x16" concrete prisms were made using steel molds, which will be tested using the ultrasonic method. And total of eleven 4"x8" cylinders were casted which will be used to determine the compressive strength. Finally two samples of approximately 1500 grams of concrete each were used for the microwave test to determine the $\mathrm{w} / \mathrm{c}$ ratio of the mix. As for the second casting, total of $1.8-\mathrm{ft}^{3}$ of SCC was produced. The same number of the 3" 4 " $\times 16$ " specimens was casted for the purpose of the ultrasonic test. And more than ten 4"x8" cylinders for the compressive strength test. And approximately two samples of 1500 grams each for the microwave tests. Both mix designs for the two different castings are shown in the tables below.

Table 3.1 - Theoretical Mix Design for $1.8 \mathrm{ft}^{3}$ Conventional Concrete

\begin{tabular}{|c|ll|}
\hline Material & \multicolumn{2}{|c|}{ Amount } \\
\hline Cement & 22.67 & $\mathrm{lb}$ \\
\hline Fly ash & 11.2 & $\mathrm{lb}$ \\
\hline Coarse Aggregate & 118.86 & $\mathrm{lb}$ \\
\hline Sand & 94.02 & $\mathrm{lb}$ \\
\hline Water & 13.62 & $\mathrm{lb}$ \\
\hline AEA & 5.61 & $\mathrm{ml}$ \\
\hline Retarder & 30.04 & $\mathrm{ml}$ \\
\hline WRA & 30.04 & $\mathrm{ml}$ \\
\hline
\end{tabular}


Table 3.2 - Theoretical Mix Design for $1.8-\mathrm{ft}^{3}$ SCC

\begin{tabular}{|c|lc|}
\hline Material & \multicolumn{2}{|c|}{ Amount } \\
\hline Cement & 49 & $\mathrm{lb}$ \\
\hline Silica Fume & 5 & $\mathrm{lb}$ \\
\hline $\begin{array}{c}\text { Coarse Aggregate } \\
\text { (\#57) }\end{array}$ & 99.95 & $\mathrm{lb}$ \\
\hline Sand & 101.37 & $\mathrm{lb}$ \\
\hline Water & 18.49 & $\mathrm{lb}$ \\
\hline HRWR & 159.68 & $\mathrm{ml}$ \\
\hline Air & 23.95 & $\mathrm{ml}$ \\
\hline
\end{tabular}

\subsubsection{Tests During SCC Casting}

\section{(1) Slump Flow Test}

The slump flow test can be used to measure the durability of freshly mixed concrete. It can be also used to determine the viscosity of the SCC mixture by measuring the time that takes the concrete to spread within a specific spread diameter. The slump flow test of SCC requires the same equipment used for the slump flow test of conventional concrete and its standardized as ASTM C1611. The equipment needed as shown in Figure 3.1 are a slump cone and nonabsorbent smooth, rigid plate that has minimum diameter of $915 \mathrm{~mm}$ (36 in) and marked with a circle showing the central location for the slump cone. The slump cone was placed on the center of the board with the small hole facing down and held hard before being filled with concrete. The cone was filled and the excess material was removed from the testing area. Then it was removed up above the board at a distance of $225 \mathrm{~mm}$ with a stable motion so that it doesn't affect the concrete's flow. After waiting for the concrete to stop flowing, the largest diameter of the resulting circular spread of concrete was measured. Then a second diameter of the circular 
spread of concrete was measured at approximately a perpendicular angle to the first diameter. The slum flow could be calculated by taking the average between the two diameters as shown by equation (4) provided by ASTM C1611 (ASTM, 2014). The slump flow of the SCC casting was measured to be 23 inches that is within the acceptable range which is $22-30$ inches.
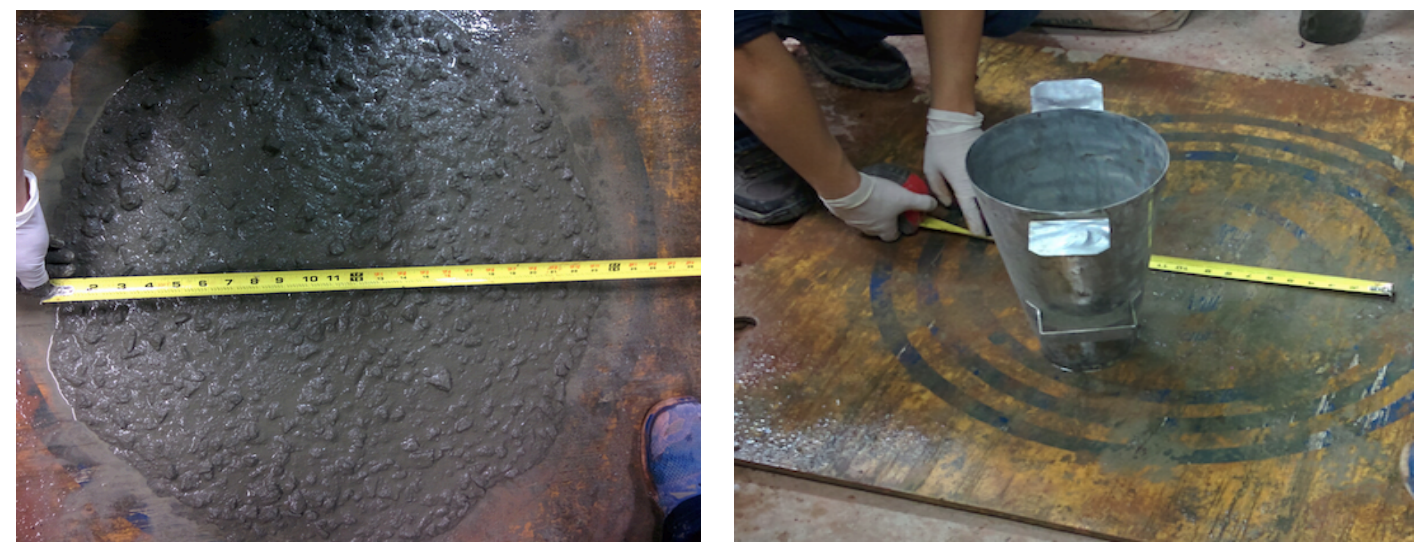

Figure 3.1 - SCC Slump Flow Test

$$
\text { Slump flow }=\frac{\left(d_{1}+\mathrm{d} 2\right)}{2}
$$

Where:

$\mathrm{d}_{1}=$ the largest diameter of the circular spread of the concrete (in)

$d_{2}=$ the circular spread of the concrete at an angle perpendicular to $d^{1}$ (in)

\section{(2) $T_{50}\left(T_{20}\right)$}

During the slump flow test, the viscosity of the SCC mixture was determined by measuring the time it took the concrete to reach the spread diameter of $50 \mathrm{~cm}(20 \mathrm{inch})$ from the moment the slump cone was removed and that's called $T_{50}\left(T_{20}\right)$. The acceptable time typically 
varies between 2 and 7 seconds for a stable SCC and the $\mathrm{T}_{50}$ of the current laboratory SCC mix was recorded to be 6.5 seconds which indicates that the mix had an acceptable viscosity and good flowability.

\section{(3) Visual Stability Index (VSI)}

The visual stability index is used to test the resistance of the mix to segregation and can be determined when the slump flow test is done. The VSI value that would be assigned to the mix ranges from 0 to 3 depending on the condition of the mix spread. 0 would be given when the mix spread is highly stable without any signs of bleeding or segregation and 3 would represent a highly unstable spread with obvious segregation signs. According to ASTM C1611 the VSI would be determined after the concrete stops spreading. It could be assigned depending on three main factors, the distribution of coarse aggregate within concrete mass, the distribution of mortar fraction, and the bleeding characteristics. The VSI of the SCC mix was determined to be 1 to 2 by comparing the SCC final spread with the VSI as shown in Figure 3.2 below (ASTM, 2014)..
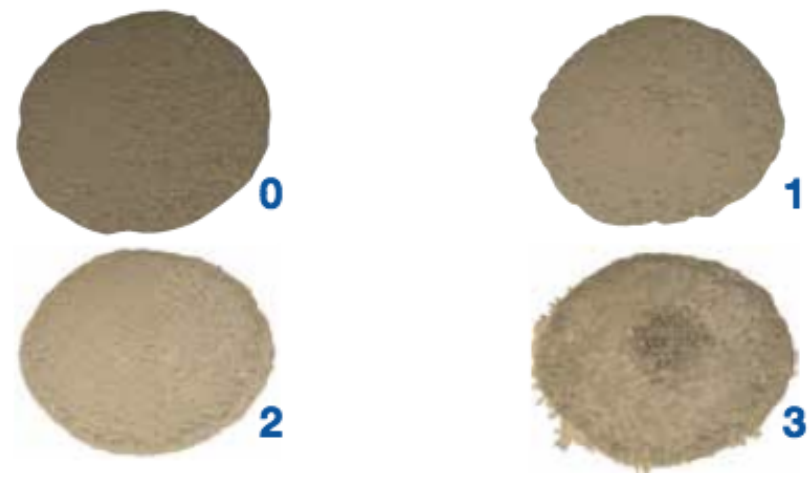

Figure 3.2 - Visual Stability Index Values (ASTM, 2014). 


\section{(4) J-ring Test}

The J-ring test is standardized as ASTM C1612 and is used for the determination of the passing ability of SCC; its ability to flow under its own weight and fill all spaces within the working area. The same equipment used for the slump flow test is needed for this test in addition to the steel J-ring. And also the same procedure used for the slump flow test but with placing the steel J-ring around the flow cone. The J-ring for the SCC casting was measured to be 16.5 inches and that brings the difference between slump flow and J-ring to 6.5 inches which means a noticeable to extreme blocking based on Table 3.3 below. That high blocking was the result of using \#57 coarse aggregates instead of \#67. The current SCC mix does not satisfy the J ring requirement. \#57 coarse aggregate is not suitable for SCC.

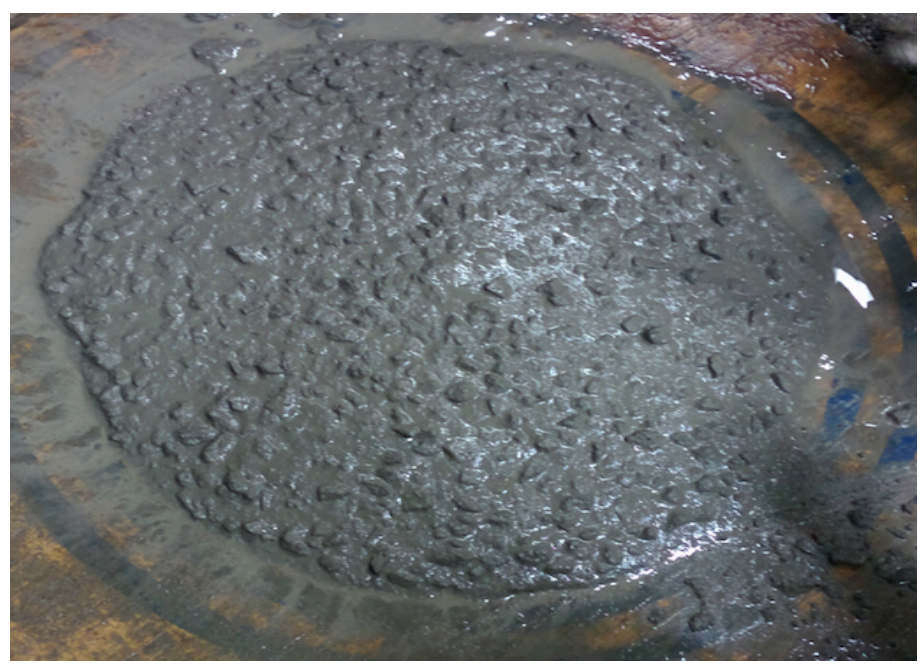

Figure 3.3 - SCC Slump flow Final Spread 


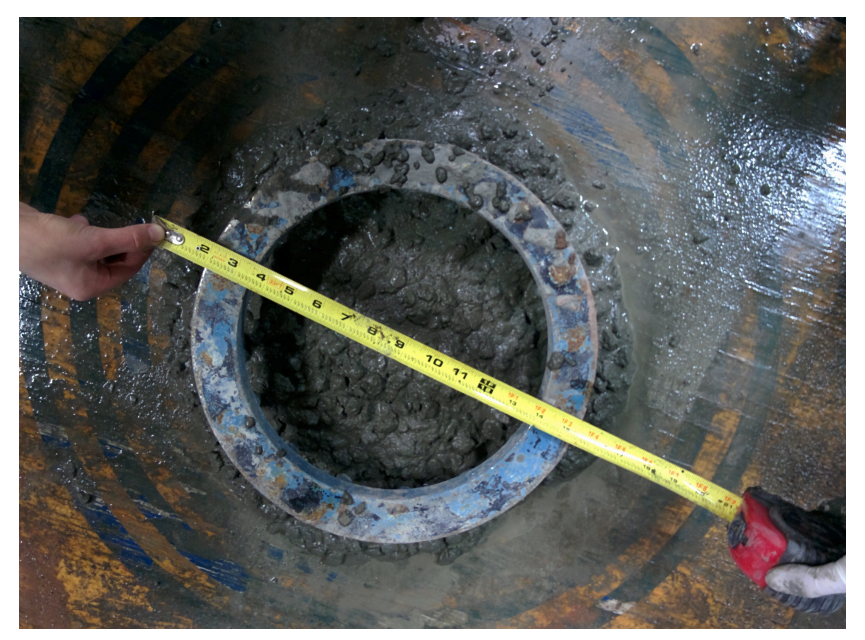

Figure 3.4 - SCC J-ring Test

Table 3.3 - Blocking Assessment (ASTM, 2014)

\begin{tabular}{|c|c|}
\hline $\begin{array}{c}\text { Difference Between Slump Flow } \\
\text { and J-Ring Flow }\end{array}$ & Blocking Assessment \\
\hline 0 to 1 in $(0$ to $25 \mathrm{~mm})$ & No visible blocking \\
\hline$>1$ to 2 in $(>25$ to $50 \mathrm{~mm})$ & Minimal to noticeable blocking \\
\hline$>2$ in $(>50 \mathrm{~mm})$ & Noticeable to extreme blocking \\
\hline
\end{tabular}

\section{(5) Air-Content Test}

The air content test is important since the freeze-thaw durability and compressive strength of concrete are influenced by its air content. According to ASTM C231 - Standard Test Method for Air Content of Freshly Mixed Concrete by the Pressure Method (ASTM, 2014). A type B pressure meter was used to determine the air content during the SCC casting. The measured air content of the fresh SCC was approximately equal to $2.7 \%$ which was considered to be low. A typical air content for concrete with a $3 / 4$-inch maximum-size aggregate would equal to $6 \%$. 


\subsubsection{Compressive Strength of Fly Ash and SCC Castings}

The compressive strength of both conventional concrete and SCC were tested at 1, 3, 7, 14 and 28 days at West Virginia University's Concrete Laboratory according to ASTM C39 using the cylindrical concrete specimens (ASTM, 2011). The different materials used to develop both concretes would affect the compressive strength of each in addition to the effects caused by the different air contents and $\mathrm{w} / \mathrm{c}$ ratios.

Table 3.4 - Compressive Strength of conventional concrete and SCC.

\begin{tabular}{|c|c|c|}
\hline Day & $\begin{array}{c}\text { Measured } \\
\text { Compressive } \\
\text { Strength, Fly } \\
\text { Ash (psi) }\end{array}$ & $\begin{array}{c}\text { Measured } \\
\text { Compressive } \\
\text { Strength, SCC } \\
\text { (psi) }\end{array}$ \\
\hline $\mathbf{1}$ & 1250 & 5000 \\
\hline $\mathbf{3}$ & 2775 & 7958.3 \\
\hline $\mathbf{7}$ & 3537.5 & 9125 \\
\hline $\mathbf{1 4}$ & 4041.7 & 10000 \\
\hline $\mathbf{2 8}$ & 4583.3 & 12500 \\
\hline
\end{tabular}

The concrete specimens used to test the compressive strength were cured at the same laboratory temperature for both SCC and fly ash castings. It is shown from Table 3.4 that generally SCC has a much higher compressive strength than conventional concrete; SCC has a static compressive strength of 5000 psi at day 1 , which is higher than what fly ash has at 14 days. The w/cm is about 0.342 for SCC and 0.402 for fly ash. However, the compressive strength of SCC was much higher as shown from the table. That's usually because of, high cement content 
in SCC and low water cement ratio which improves the interface between the aggregate and hardened paste.

\subsection{Microwave Test to Determine w/c}

\subsubsection{Test Procedure}

The main objective of this experiment is to be able to determine whether the microwave method would be an effective and accurate method for the rapid determination of w/c ratio of freshly mixed concrete; both conventional and SCC. There are many concrete applications that would require a rapid and on-site determination of w/c ratio due to the effects that might occur as a result of varying w/c ratios such as large concrete constructions or when using SCC. It would also help determine the reliability of the concrete that is being used and whether or not it satisfies the job requirements, which would help avoid any future errors.

The experiment does not require a lot of equipment and could be done with a simple setting; it requires a microwave oven with strength of 900 watts or more, glass trays that could be used for the microwave and be able to hold approximately 1600 grams concrete sample, heatresistant mittens, grinding pestle, and a weighing device with an accuracy of 0.1 grams. The procedures used for this experiment are summarized below based on AASHTO T 318-02:

1. Measure the weight of the clean and dry glass tray and record it as WS.

2. Place tray on the scale and zero it. Place $1500 \pm 100$ grams of sample and test it.

3. Determine the weight of both the concrete sample and glass tray and record it as WF.

4. Place the sample with the glass tray in the microwave at a 900 -Watt power for $5.0 \pm 0.5$ minutes. 
5. After the first drying cycle, remove the sample from microwave for no more than 60 seconds. Separate large aggregates from mortar using the grinding pestle and break all clumps to disclose the maximum amount of mortar. It is important to make sure not to lose any amount of the sample while mixing.

6. Return sample to the microwave for the second trial: leave in the microwave at a 900Watt power for another $5.0 \pm 0.5$ minutes. Then remove the glass tray and stir the sample for no more than 60 seconds.

7. Now place the sample in the microwave at a 900 -Watt power for $2.0 \pm 0.5$ minutes.

8. Remove the tray with the sample and stir to disclose the mortar. Then record the mass of the tray and sample.

9. Steps 7 through 9 must be repeated until the weight change is less than 1 gram. Then that should be recorded as WD to end the experiment.

The water content of the sample in this method could be calculated using a specific equation as shown below:

$W C=\frac{100 *(W F-W D)}{(W F-W S)}$

Where:

$\mathrm{WC}=$ water content of sample as a percentage

$\mathrm{WF}=$ mass of glass tray + fresh test sample

$\mathrm{WD}=$ mass of glass tray + dry sample

$\mathrm{WS}=$ mass of glass tray + cloth

The theoretical amount of each material used in the sample could be determined by knowing the distribution of those materials using the percentage of each material within the mix. For example if the total material batched is 2540 grams of the mortar mix made at the laboratory 
and total of fine aggregates is 1600 grams, the percentage of fine aggregate would approximately equal to $63.0 \%$ of the mortar sample. How much of each material occur in the sample could be determined by multiplying theoretical content of each by the size of sample. The determination of the amount of free water and the total evaporable water is dependent of the previous calculations. Following this further, the calculated free water would be used to determine $\mathrm{w} / \mathrm{cm}$ ratio of mortar mix, which could be done by dividing it by theoretical cementitious material content of sample.

For the purpose of this experiment, it is assumed that small amount of water will be lost as a result of the reactions that could happen during mixing. So all water was assumed to be regained. A spreadsheet was created for the calculations of the w/c ratio of the mix using the method described earlier which includes calculating: theoretical cement content, fine aggregate, larger aggregate, total water, and free water in the sample. An example of the spreadsheet used for the calculations of this experiment is shown in Jared's thesis (Hershberger, 2015).

\subsubsection{Experimental Data and Result}

The equations and procedure used for the determination of water to cement ratio are the same for both experiments done with fly ash and SCC. The equation which was used to calculate the free water within the concrete samples was done by subtracting both the theoretical fine aggregate content multiplied by the fine aggregate SDD and the theoretical large aggregate multiplied by the large aggregate SDD. This process is represented in equation form below.

$S F W=\Delta W-\left[\frac{S W * M F A * S S D F A}{M T W}\right]-\left[\frac{S W * M L A * S S D L A}{M T W}\right]$

Where: 
$\mathrm{SFW}=$ sample free water (grams)

$\Delta \mathrm{W}=$ total weight change over experiment (grams)

$\mathrm{SW}=$ sample weight (grams)

$\mathrm{MFA}=$ mix design fine aggregates content $\left(\mathrm{lb} / \mathrm{yd}^{3}\right)$

$\mathrm{MTW}=$ mix design total weight $\left(\mathrm{lb} / \mathrm{yd} \mathrm{d}^{3}\right)$

SSDFA $=$ saturated surface dry of fine aggregate $(1.9 \%$ for both experiments $)$

$\mathrm{MLA}=$ mix design large aggregates content $\left(\mathrm{lb} / \mathrm{yd}^{3}\right)$

SSDLA $=$ saturated surface dry of large aggregate $(0.5 \%$ for both experiments $)$

After the free water in the sample is determined, the theoretical cementitious can be readily calculated using the process described above. The equation used to determine the cementitious content is shown below.

$C M S=\frac{M C * S W}{M T W}$

Where:

$\mathrm{CMS}=$ theoretical sample cementitious content (grams)

$\mathrm{MC}=$ mix design cementitious content $\left(\mathrm{lb} / \mathrm{yd}^{3}\right)$

$\mathrm{SW}=$ sample weight (grams)

$\mathrm{MTW}=\operatorname{mix}$ design total weight $\left(\mathrm{lb} / \mathrm{yd}^{3}\right)$

The calculated $\mathrm{w} / \mathrm{cm}$ ratio can then be found using the following equation. 
Calculated $w / c m=\frac{S F W}{C M S}$

Where:

$\mathrm{SFW}=$ sample free water (grams)

$\mathrm{CMS}=$ theoretical sample cementitious content (grams)

The error of the test results with relation to the actual $\mathrm{w} / \mathrm{cm}$ is calculated using the equation shown below.

$\%$ Error $=\frac{\text { Calculated } w / \mathrm{cm}-\text { Actual } w / \mathrm{cm}}{\text { Actual } w / \mathrm{cm}}$

By dividing the sample free water by the theoretical cementitious content, the theoretical w/cm ratio can readily be calculated at each step of the experiment. When the change in weight of a given sample is less than 1 gram, the experiment should be done and the final calculation of the $\mathrm{w} / \mathrm{cm}$ is performed.

The same process and equations were used when testing concrete samples for all castings. The given w/c for the fly ash and SCC is 0.402 and 0.342 respectively. For the first fly ash casting, one sample was tested with a \% error of -10.5 . As for the SCC casting, two samples were tested and the maximum error observed was $12.8 \%$. The average of the magnitude of the error was found to be $10.35 \%$ for SCC. Finally for the third casting, two samples were tested with a maximum error of $-4.7 \%$. And the average of the magnitude of the error was found to be 2.45\%. The results from the three different castings are shown below in Table 3.5. 
Table $3.5-\mathrm{W} / \mathrm{cm}$ results from concrete samples

\begin{tabular}{|c|c|c|c|c|c|c|}
\hline & Sample & $\begin{array}{c}\text { Sample } \\
\text { Size } \\
(\mathrm{g}) \\
\end{array}$ & $\begin{array}{c}\text { Sample } \\
\text { Free } \\
\text { Water } \\
(\mathrm{g}) \\
\end{array}$ & $\begin{array}{l}\text { Theoretical } \\
\text { Cementitious } \\
\text { Content } \\
\text { (g) }\end{array}$ & $\begin{array}{c}\text { Calculated } \\
\mathbf{w} / \mathrm{cm}\end{array}$ & $\%$ Error \\
\hline $\begin{array}{c}\text { Fly Ash } \\
\text { (Casting \#1) }\end{array}$ & $\begin{array}{c}\text { Sample } \\
\# 1\end{array}$ & 1525.1 & 72.3 & 201.1 & 0.360 & -10.5 \\
\hline \multirow{2}{*}{$\begin{array}{c}\text { SCC } \\
(\text { Casting \#2) }\end{array}$} & $\begin{array}{c}\text { Sample } \\
\# 1\end{array}$ & 1539.2 & 98.2 & 204.6 & 0.315 & -7.9 \\
\hline & $\begin{array}{c}\text { Sample } \\
\# 2\end{array}$ & 1560.5 & 127 & 207.4 & 0.386 & 12.8 \\
\hline \multirow{2}{*}{$\begin{array}{c}\text { Fly Ash } \\
\text { (Casting \#3) }\end{array}$} & $\begin{array}{c}\text { Sample } \\
\# 1\end{array}$ & 1426.8 & 78.4 & 187.7 & 0.383 & -4.7 \\
\hline & $\begin{array}{c}\text { Sample } \\
\# 2\end{array}$ & 1552.3 & 75.5 & 204.2 & 0.401 & -0.2 \\
\hline
\end{tabular}

As we can see from the table above that the two samples of SCC showed different accuracy when compared with both results for Fly Ash. One reason might be considered behind this is the fact that self-consolidating concrete is more sensitive to changes in aggregate moisture contents than conventional concrete. One or two rocks, added or removed from the test sample can produce a significant error in the test result. There are several sources of error in the results of the microwave method including loss of material while drying and processing, nonrepresentative aggregate content in the sample, and not correcting the measured water for water absorbed by aggregates.

In the past, researches have tried to modify the method by using sieved mortar samples to determine whether these samples could provide more accurate results or not. It was predicted that testing mortar samples potentially might produce more accurate results. But for the purpose of this study some other modifications were applied to the method to determine whether they could give more accurate results or not. The same samples that were tested using the microwave 
were sieved out after they become fully dry using a No.4 sieve to separate large aggregates and a No.270 to separate fine aggregates. Then the $w / \mathrm{cm}$ was calculated based on the new values of large aggregates, fine aggregates, free water, and cementitious material. Those results were compared to the first results from the microwave testing to determine which would provide more accurate results. The samples from the Fly Ash casting and SCC casting were tested using this method and results are shown in Table 3.6 below.

Table 3.6 - W/cm results for sieved samples

\begin{tabular}{|c|c|c|c|c|c|c|}
\hline & Sample & $\begin{array}{c}\text { Sample } \\
\text { Size } \\
\text { (g) }\end{array}$ & $\begin{array}{c}\text { Sample } \\
\text { Free Water } \\
\text { (g) }\end{array}$ & $\begin{array}{c}\text { Theoretical } \\
\text { Cementitious } \\
\text { Content } \\
\text { (g) }\end{array}$ & $\begin{array}{c}\text { Calculated } \\
\text { w/cm }\end{array}$ & \% Error \\
\hline $\begin{array}{c}\text { Fly Ash } \\
\text { (Casting \#1) }\end{array}$ & $\begin{array}{c}\text { Sample } \\
\# \mathbf{1}\end{array}$ & 1525.1 & 72.8 & 151.8 & 0.479 & 19.15 \\
\hline \multirow{2}{\text{SCC}}{$\begin{array}{c}\text { Sample } \\
\text { \#1 }\end{array}$} & 1539.2 & 96.6 & 163.1 & 0.592 & 73.24 \\
\cline { 2 - 7 } (Casting \#2) & $\begin{array}{c}\text { Sample } \\
\text { \#2 }\end{array}$ & 1560.5 & 126.5 & 156.8 & 0.768 & 124.52 \\
\hline
\end{tabular}

It can be observed from Table 3.6 that the modified method using sieved samples could not produce more accurate results. The results for testing sieved samples of SCC showed more error than the sieved samples for Fly Ash concrete. Further investigation is needed to modify this method to obtain an accurate quantity of the cement powder from the sieved samples.

It was observed that the results for concrete samples would differ than those for sieved samples for both conventional concrete and SCC. The two SCC sieved samples provided results with different accuracy. The reason behind that might be the sampling error; the proportions may not be uniform when getting the two samples from the same batch of concrete mix. The reason why the sieved method provides an inaccurate result is that the amount of powder that is being 
extracted from the large aggregates and the sand particles of the sample is not the correct cement powder amount. It is hard to get all of the powder out of the large aggregates and sand particles.

\subsection{Ultrasonic Method Experiment}

\subsubsection{Test Procedure}

The main purpose of this experiment is to measure the travel time of pulse of longitudinal ultrasonic waves passing through concrete samples, which would be used to determine the Young's modulus and compressive strength of concrete samples being tested. The ultrasonic pulse velocity method allows the examination of material homogeneity and is useful for defects identification. This method enables a continuous evaluation of the concrete performance during the entire structure's service life.

The ultrasonic pulse velocity experiment could be performed with a simple setting that includes three main components that would help get the right measurements: 1) two transducers, 2) a pulser-reciever unit, and 3) the data acquisition system as shown in Figures 3.5 and 3.6 below. The suitable equipment and standard procedures needed for this experiment are described in ASTM C597 (ASTM , 2009). The equipment that are used in the test must create a system that has the ability to generate a pulse, transmit this pulse to the concrete sample, receive the pulse, measure and display the time traveled. Repetitive voltage pulses are going to be formed and transformed as wave bursts using the transmitting transducer. The transmitting and receiving transducers must be coupled to the concrete using a suitable medium. The waves are going to be transformed as mechanical energy, which would be converted back to electrical pulses with the same frequency. 


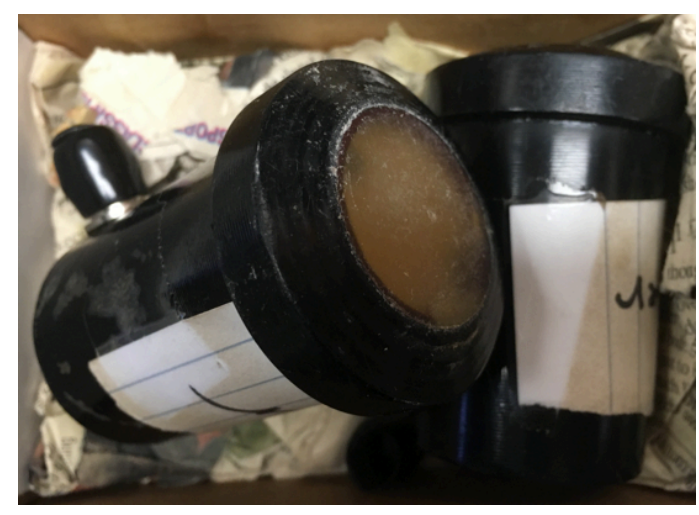

Figure 3.5 - Two Transducers
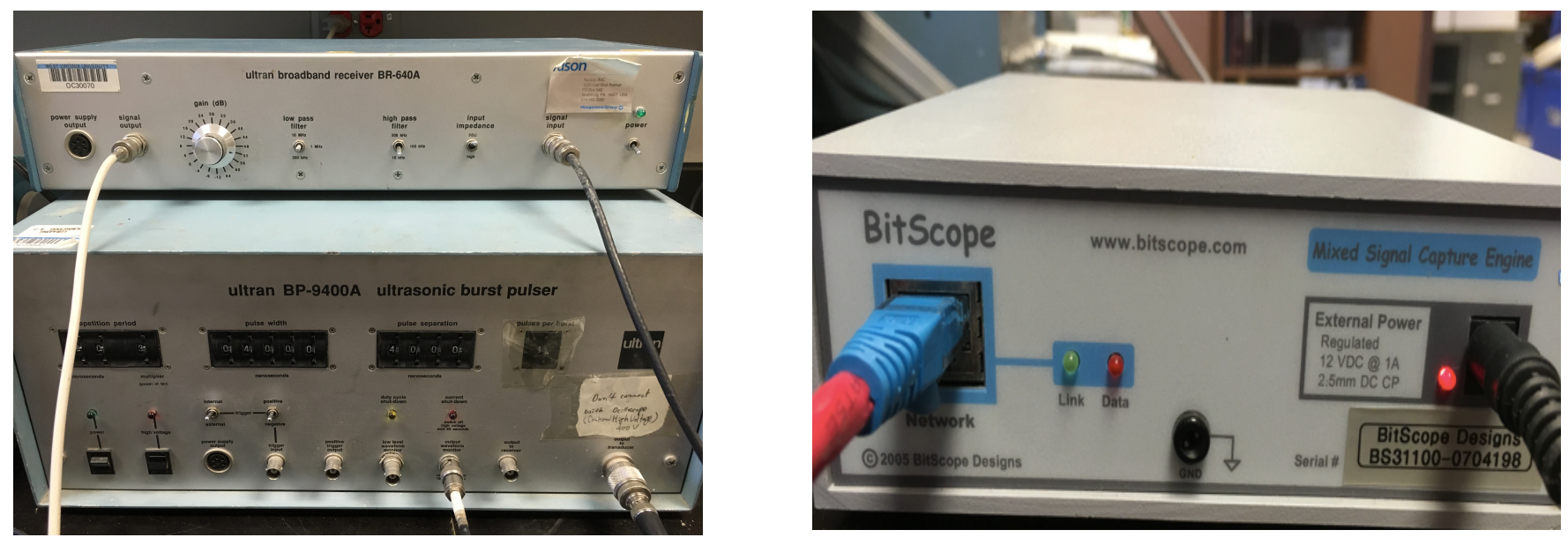

Figure 3.6 - A pulser-receiver unit and a data acquisition system (Bitscope)

The travel time between the beginning and the reception of the pulse can be measured by the electronic timing device, and it can be read from an oscilloscope or a digital readout. Measuring the travel time is dependent on the detection of the compressive wave pulse, which may have very small amplitude at the beginning. When using an oscilloscope, the start of the pulse will be considered as the tangent point between the signal curve and the horizontal time 
line. On the other hand, the pulse will have a shape that triggers the timer from the edge of a pulse when using digital devices.

The wave travel time of the specimen in this test was measured using the "Bitscope" which is a test, measurement and data acquisition. A "Bitscope" application must be uploaded to the computer so that it can receive the information from the device. Every time the two sensors are placed on the concrete specimen the wave would show on the screen of the application as shown in Figure 3.7. The application captures, displays and records analog waveforms, logic traces, frequency spectra, $\mathrm{X} / \mathrm{Y}$ plots and timing diagrams. It allows users to do all sorts of signal measurements by adjusting the parameters that are available on screen. The main display of the program is shown in Figure 3.7 below which includes the waveform, logic and spectrum displays, measurements and cursors.

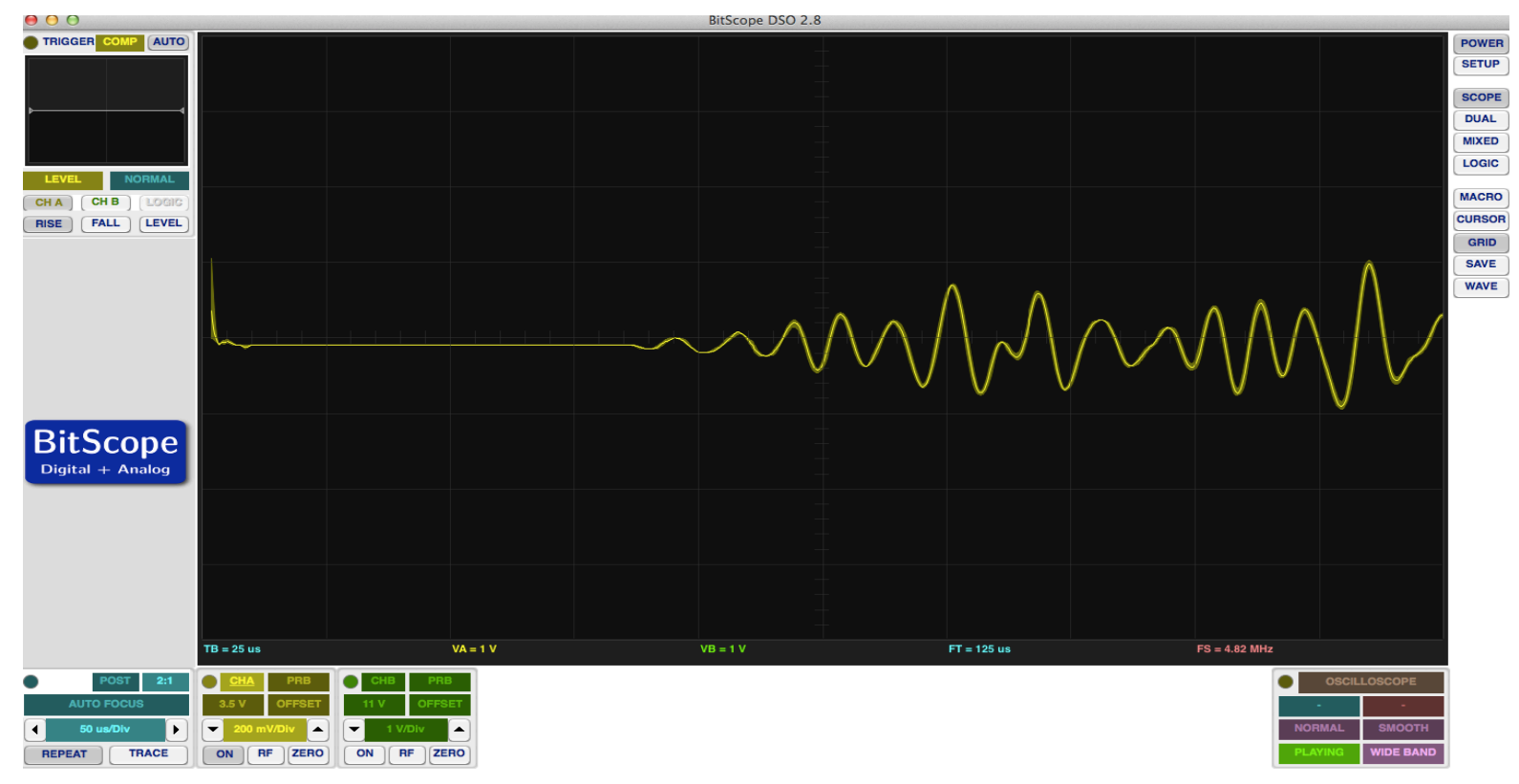

Figure 3.7 - Main Display of Bitscope 


\subsubsection{Experimental Specimens and Results}

Three 3"x4"x16" concrete specimens were prepared during both fly ash and SCC castings for the purpose of the ultrasonic pulse velocity test. After unmolding the three specimens were placed in a tank full of water (for curing) to prevent any changes in drying shrinkage and the weight and size were measured every single time before the test was performed. The length, base, and height of the specimen remained constant for the whole period of testing. The weight of the specimens remained constant too for the whole 28 days test period.

Table 3.7 - Ultrasonic Wave Velocity Results of Fly Ash (Sample \#3)

\begin{tabular}{|c|c|c|c|c|}
\hline Day & $\begin{array}{c}\text { Wave Travel } \\
\text { Time } \\
\text { (micro second) }\end{array}$ & $\begin{array}{c}\text { Velocity, } \\
V_{p} \\
(\mathbf{m} / \mathbf{s e c})\end{array}$ & $\begin{array}{c}\text { Young's Modulus, } \\
(\mathbf{v}=\mathbf{0 . 2}) \\
(\mathrm{Pa})\end{array}$ & $\begin{array}{l}\text { f'c } \\
\text { (Pa) }\end{array}$ \\
\hline 1 & 108.1 & 3759.482 & $3.08 \mathrm{E}+10$ & $4.23 \mathrm{E}+07$ \\
\hline 3 & 95 & 4277.895 & $3.99 \mathrm{E}+10$ & $7.09 \mathrm{E}+07$ \\
\hline 7 & 91.4 & 4446.390 & $4.31 \mathrm{E}+10$ & $8.27 \mathrm{E}+07$ \\
\hline 14 & 88.6 & 4586.907 & $4.58 \mathrm{E}+10$ & $9.37 \mathrm{E}+07$ \\
\hline 28 & 87.3 & 4655.212 & $4.72 \mathrm{E}+10$ & $9.94 \mathrm{E}+07$ \\
\hline
\end{tabular}

It is shown from Table 3.7, that the wave travel time decreases as time passes and concrete becomes more mature, which means that when concrete gets stronger, the wave velocity increases, and it would take less time for the wave to travel. When the pulse velocity increases, the Young's modulus of concrete specimens gets higher as the concrete gets stronger. The calculated compressive strength increases by time assuming that the strength is correlated to the Young's modulus. 
It is shown from Figure 3.8 and Figure 3.9 that there is a positive relationship between time and both wave speed and Young's modulus of concrete samples; as the time increases, wave speed and Young's modulus would increase too. Figure 3.9 represents the relationship between time and the dynamic Young's modulus of sample \#3 of fly ash concrete specimens using Poisson's ratio equal to 0.2. It is also shown from the graphs that the rate of increase in wave speed and Young's modulus values would be less when concrete samples get stronger; at 14 and 28 days the results start to become constant.

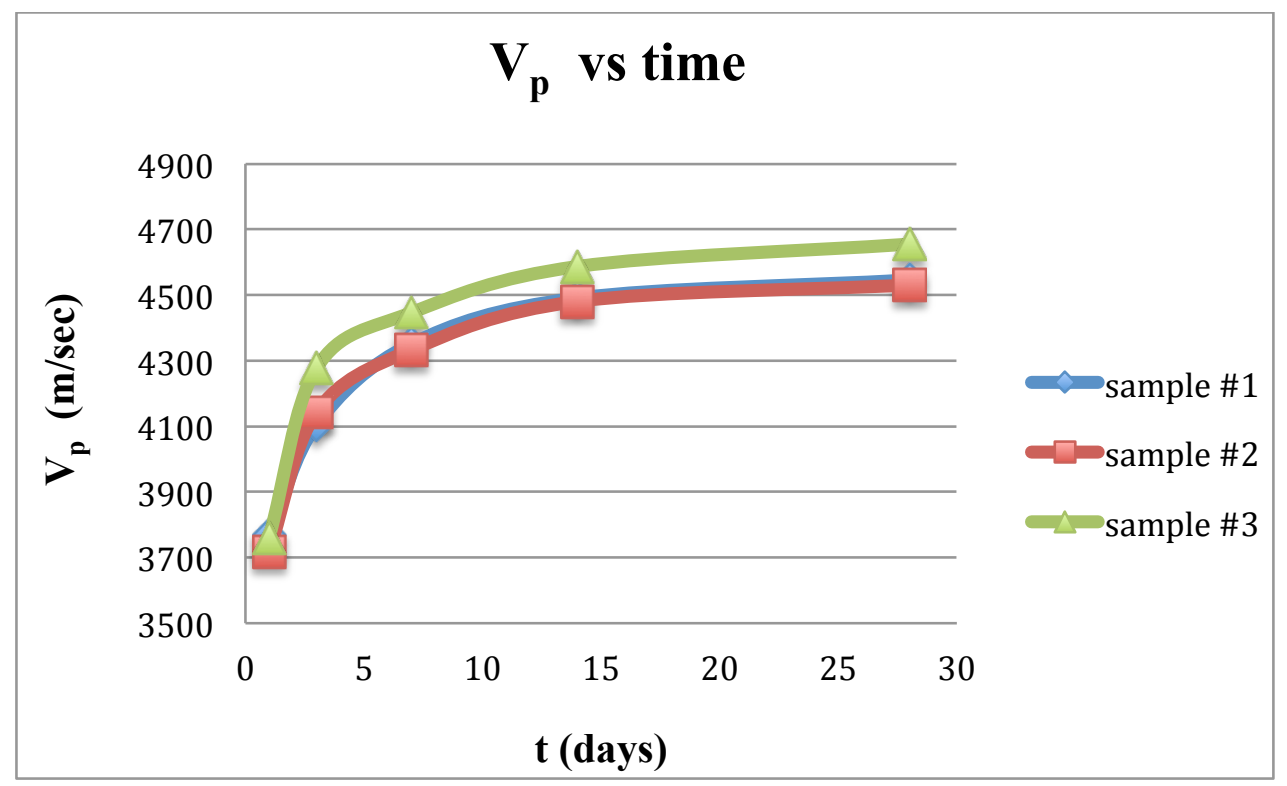

Figure 3.8 - Wave speed vs. Time of Fly Ash Concrete 


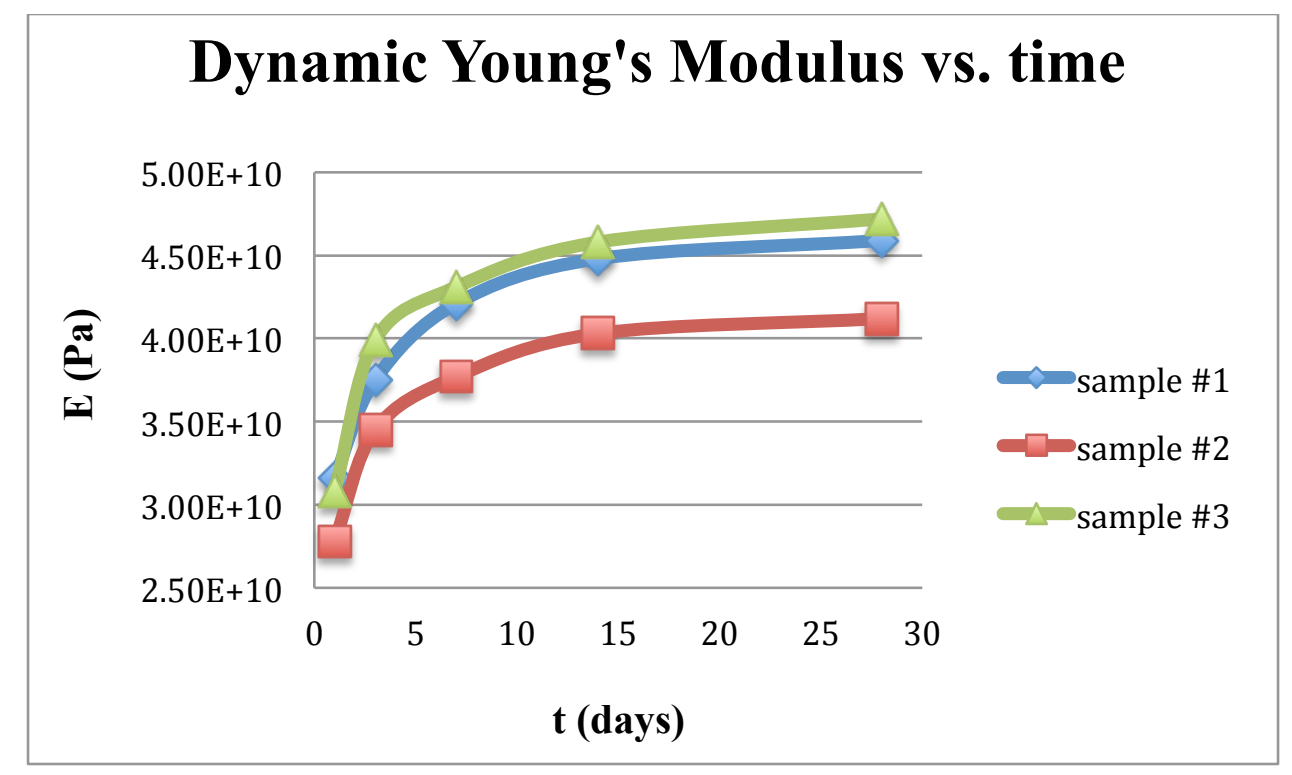

Figure 3.9 - Young's Modulus vs. Time of Fly Ash Concrete $(v=0.2)$

It is shown from Table 3.8 that the wave travels faster in self-consolidating concrete when compared with conventional concrete. SCC has also much higher values for both Young's modulus and compressive strength than TVC.

Table 3.8 - Ultrasonic Velocity Results of SCC (Sample \#3)

\begin{tabular}{|c|c|c|c|c|}
\hline Day & $\begin{array}{c}\text { Wave Travel Time } \\
\text { (micro second) }\end{array}$ & $\begin{array}{c}\text { Velocity, } \\
V_{p} \\
\text { (m/sec) }\end{array}$ & $\begin{array}{c}\text { Young's Modulus, } \\
\mathbf{v}=\mathbf{0 . 2} \\
\mathbf{( P a )}\end{array}$ & $\begin{array}{c}\mathbf{f} \text { 'c } \\
\mathbf{( P a )}\end{array}$ \\
\hline $\mathbf{1}$ & 92.3 & 4403.034 & $4.19 \mathrm{E}+10$ & $7.84 \mathrm{E}+07$ \\
\hline $\mathbf{3}$ & 86.9 & 4676.640 & $4.73 \mathrm{E}+10$ & $9.98 \mathrm{E}+07$ \\
\hline $\mathbf{7}$ & 84.4 & 4815.166 & $5.01 \mathrm{E}+10$ & $1.12 \mathrm{E}+08$ \\
\hline $\mathbf{1 4}$ & 84.3 & 4820.878 & $5.02 \mathrm{E}+10$ & $1.13 \mathrm{E}+08$ \\
\hline $\mathbf{2 8}$ & 83.8 & 4849.642 & $5.08 \mathrm{E}+10$ & $1.15 \mathrm{E}+08$ \\
\hline
\end{tabular}


It can be observed from Figures 3.10 and 3.11 that there is a positive relationship between time and both wave speed and Young's modulus of SCC samples; as the time increases, wave speed and Young's modulus would increase too. Figure 3.11 represents the relationship between time and the dynamic Young's modulus of sample \#3 of SCC specimens using Poisson's ratio equal to 0.2 . The results are almost identical to what resulted from testing Fly Ash samples. The only difference that can be shown from the graphs is that after 7 days of testing the results are becoming to be close to each other; it is almost constant between 7 and 14 days. It is also shown from the graphs that the rate of increase in wave speed and Young's modulus values would be less when concrete samples get stronger.

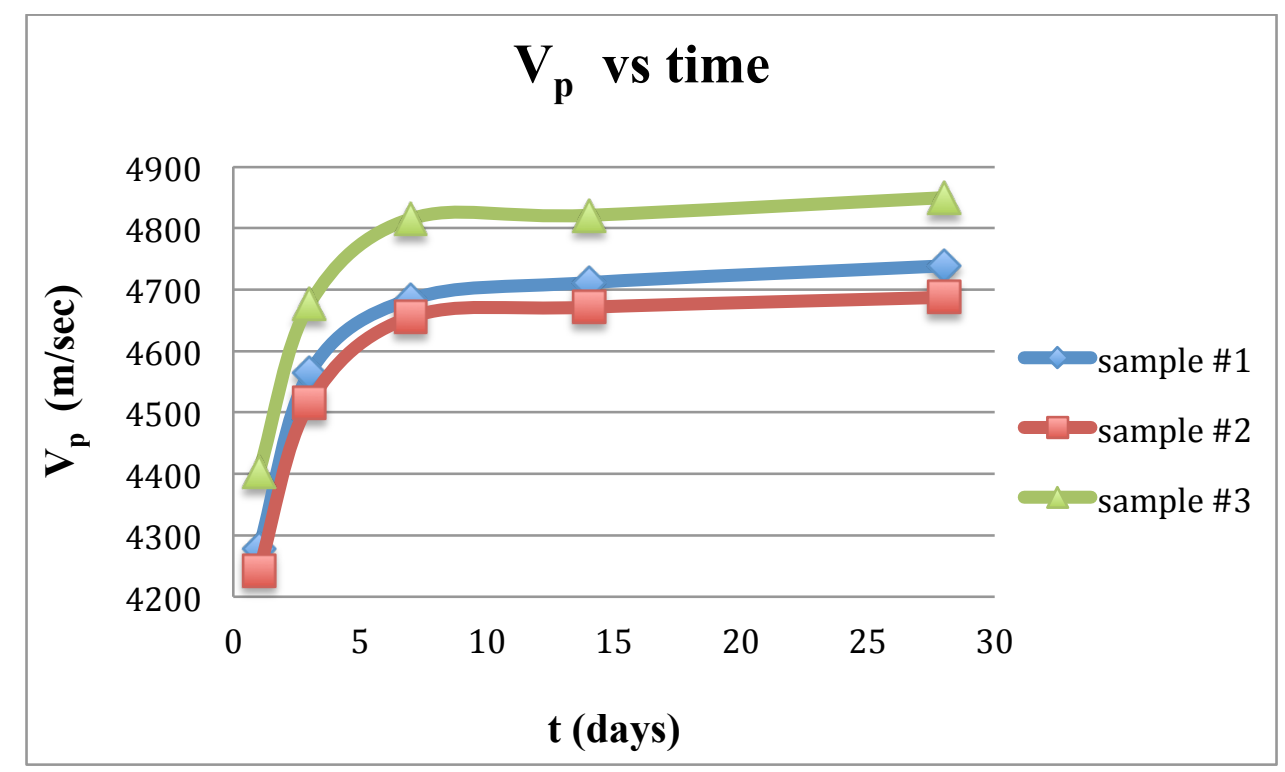

Figure 3.10 - Wave speed vs. Time of SCC 


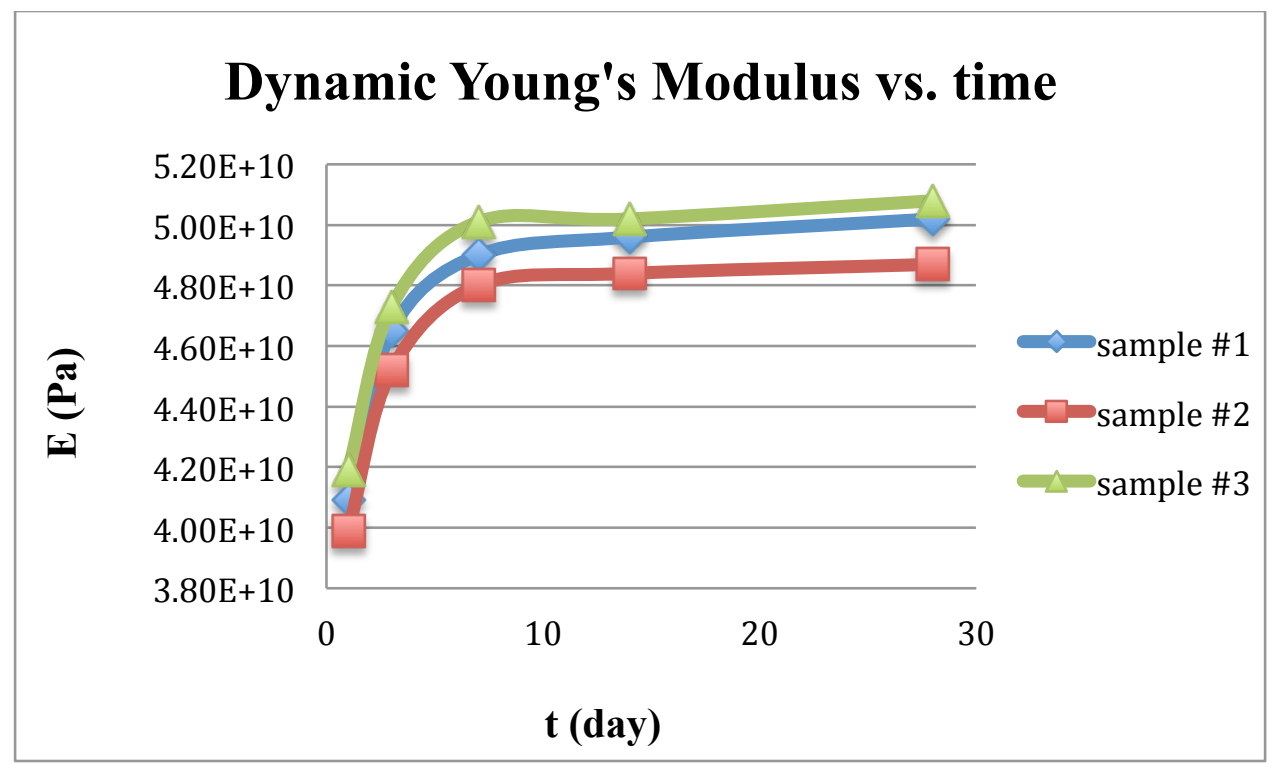

Figure 3.11 - Young's Modulus vs. Time of SCC $(v=0.2)$ 


\section{CHAPTER 4: Analysis}

\section{1 w/cm Using Microwave Method}

\subsubsection{Calculated Concrete Samples and Calculated Sieved samples}

To determine the difference between the experimental results of the concrete samples and the sieved concrete samples, both methods were plotted using the calculated concrete results versus the calculated sieved results from the table in Chapter 3. It is shown from Figures 4.1(a) and 4.1(b) that using sieved method would give higher values (more inaccurate values) than using just concrete samples in all three tests.

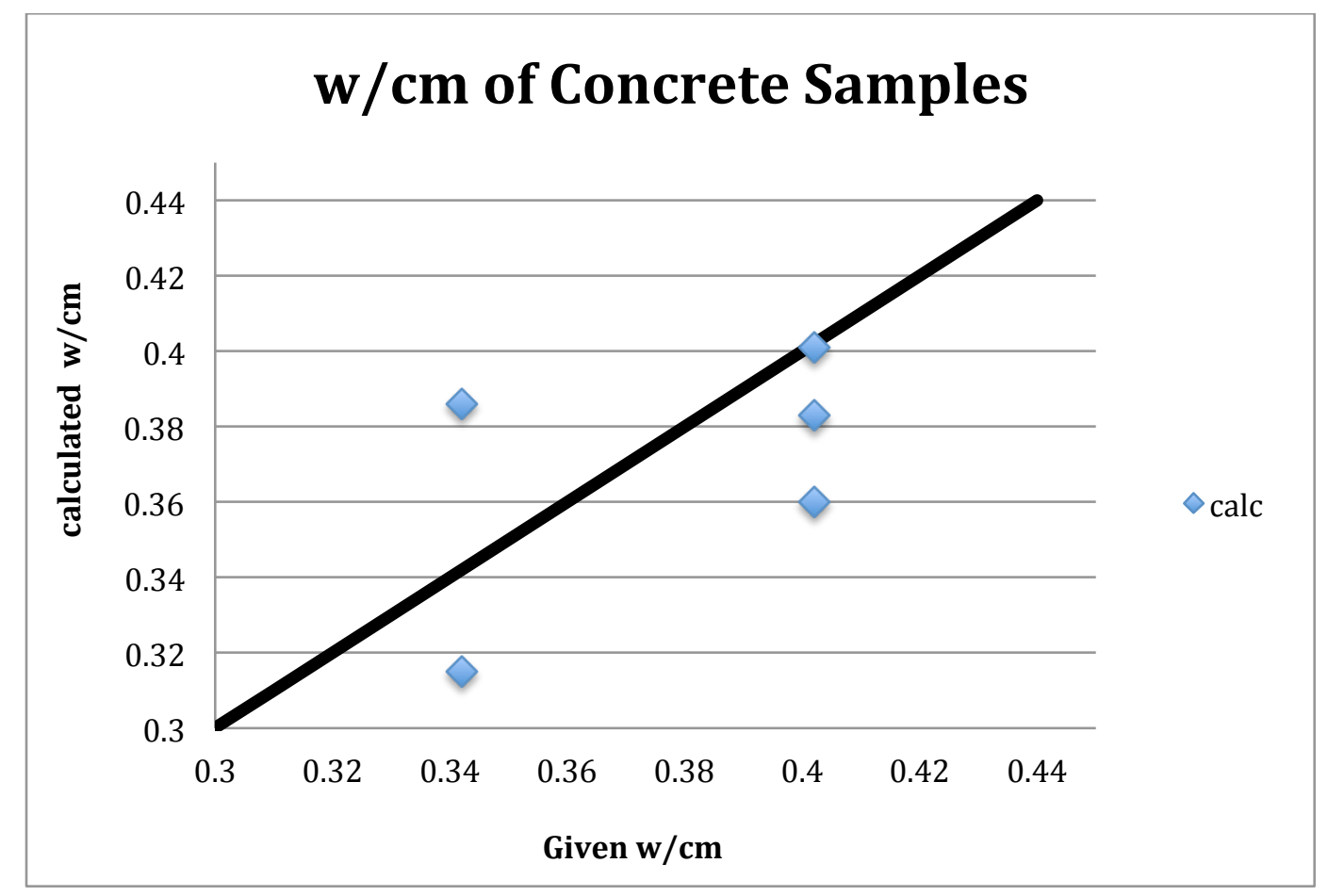

Figure 4.1 (a) - w/cm of Concrete samples 


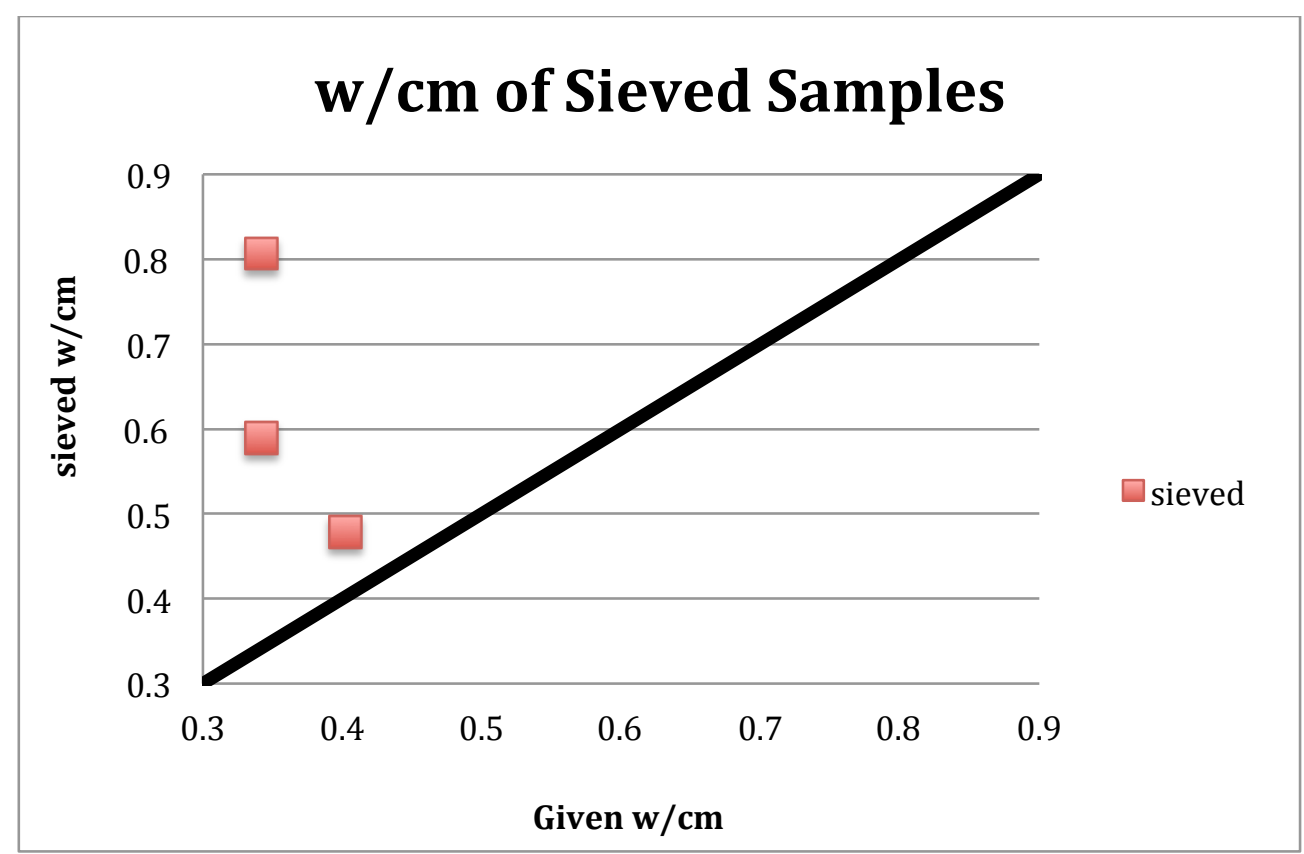

Figure 4.1 (b) - w/cm of sieved concrete samples

\subsubsection{Relationship Between Water Evaporation and Time in Microwave}

A plot was created using the resulted data after each weighing interval for each sample representing the correlation between water evaporation and microwave time as shown below in Figures 4.2 and 4.3. It is shown from the figures that as the time in microwave increase the water evaporation increases too. However it can be observed that the rate of increase decreases by the time and that's because the change is weight is reaching the point where it becomes less or equals to 1 which can be seen in Figures 4.4 and 4.5. It can be observed from the Figures below that the change in weight became less than or equal to 1 gram after the $6^{\text {th }}$ interval for SCC samples and the $5^{\text {th }}$ interval for the conventional concrete. It can also be observed that at the first 5 minutes the sample loses most of the water and then after the second 5 minutes it becomes less then after that the water loss becomes almost constant until it reaches the point where the change in weight becomes less than 1 gram and the experiment ends. 


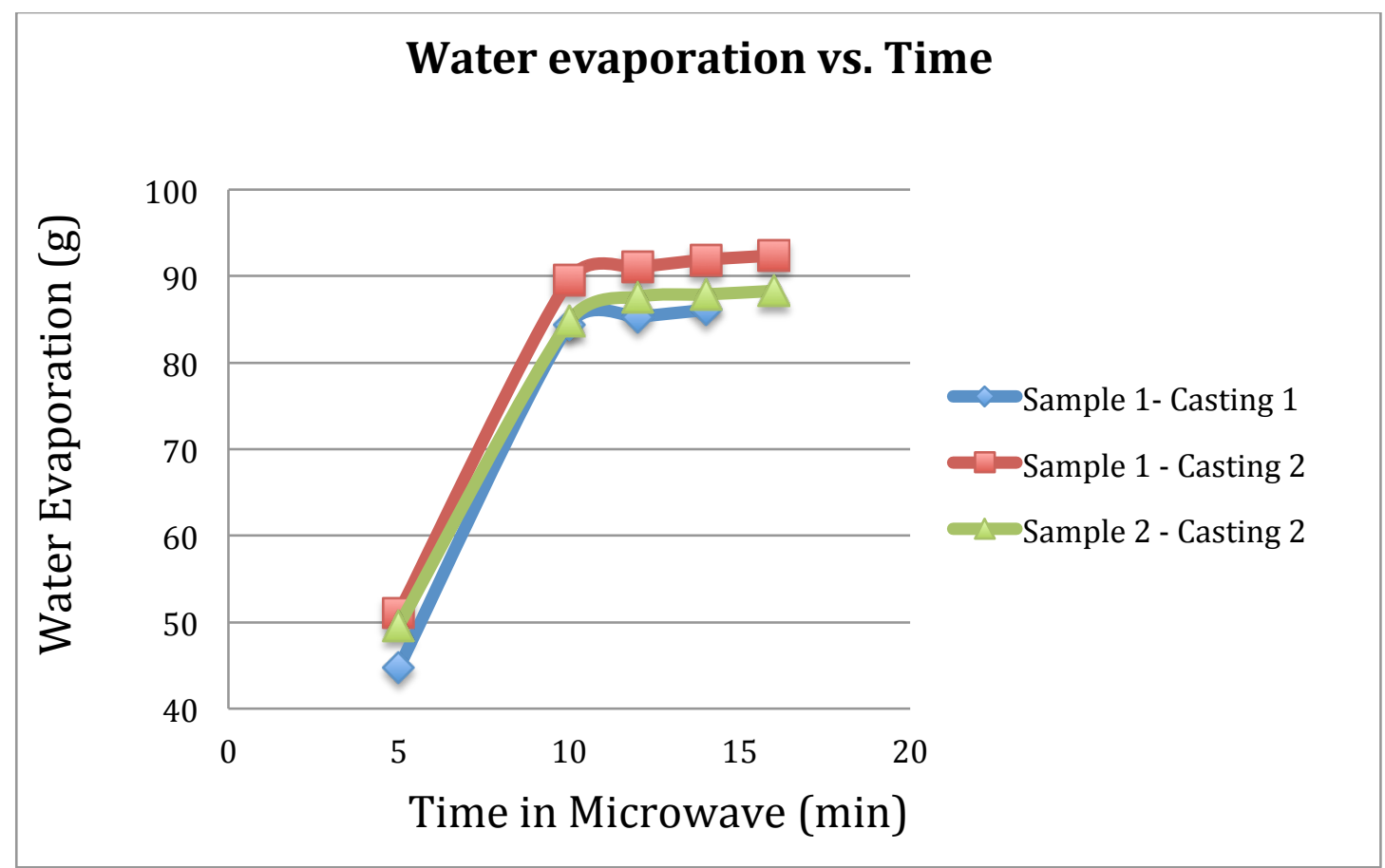

Figure 4.2 - Water Evaporation vs. Time in Microwave for Fly Ash concrete samples

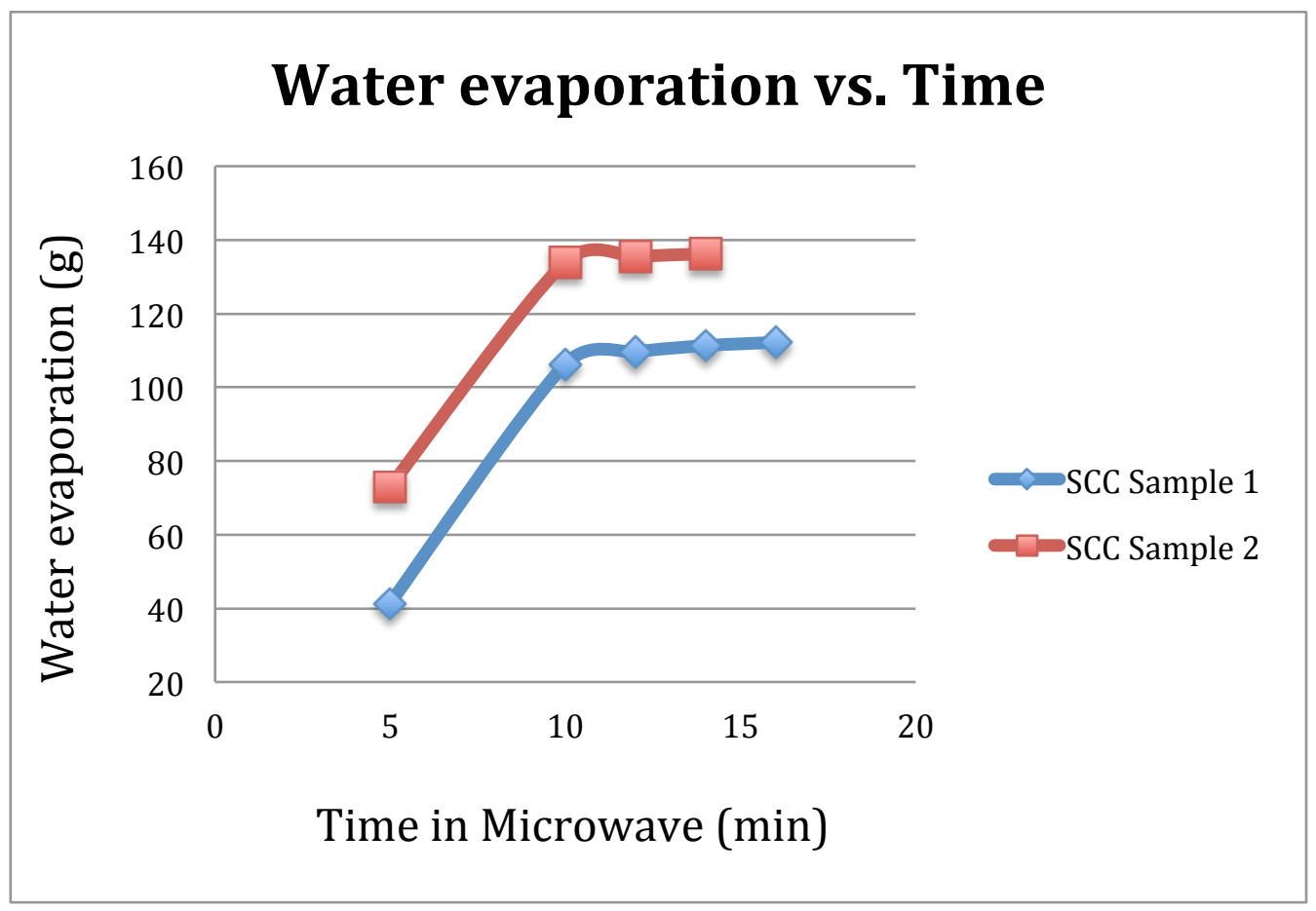

Figure 4.3 - Water Evaporation vs. Time in Microwave for SCC samples 64 


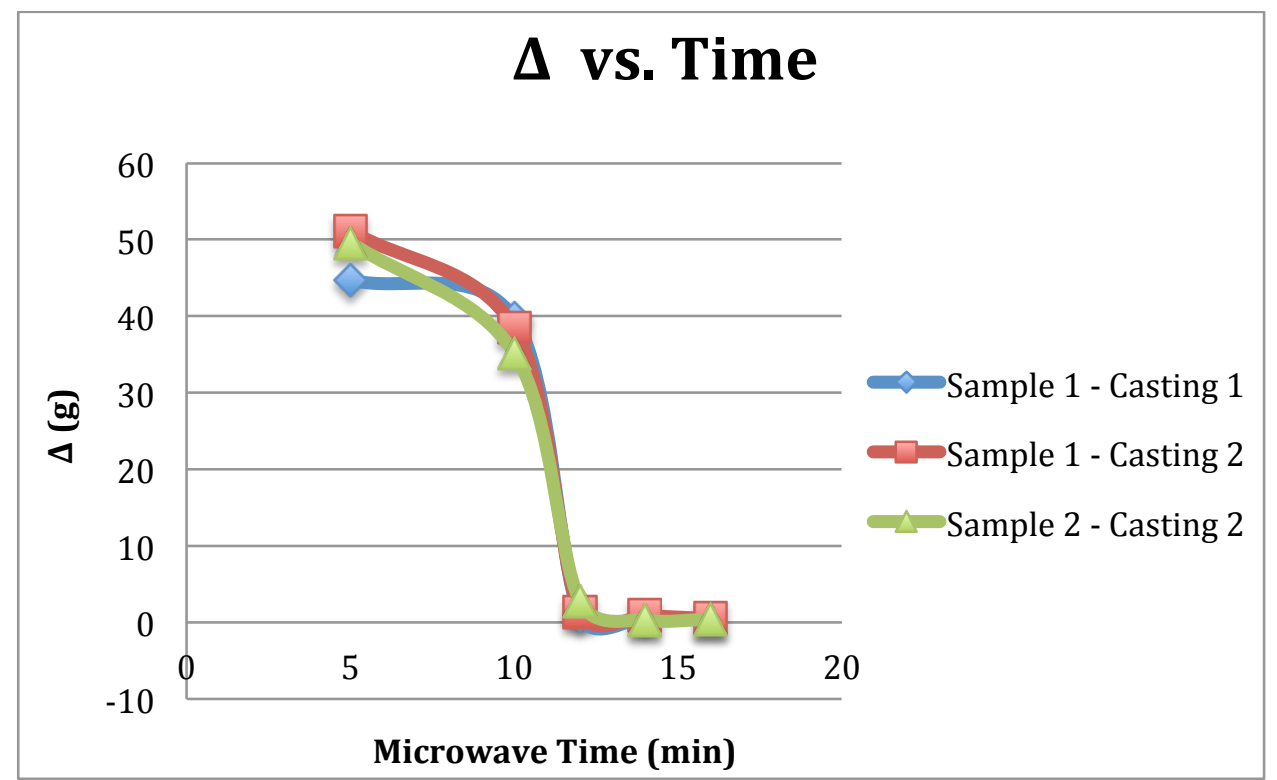

Figure 4.4 - Change in Weight vs. Microwave Time for Fly Ash Concrete samples

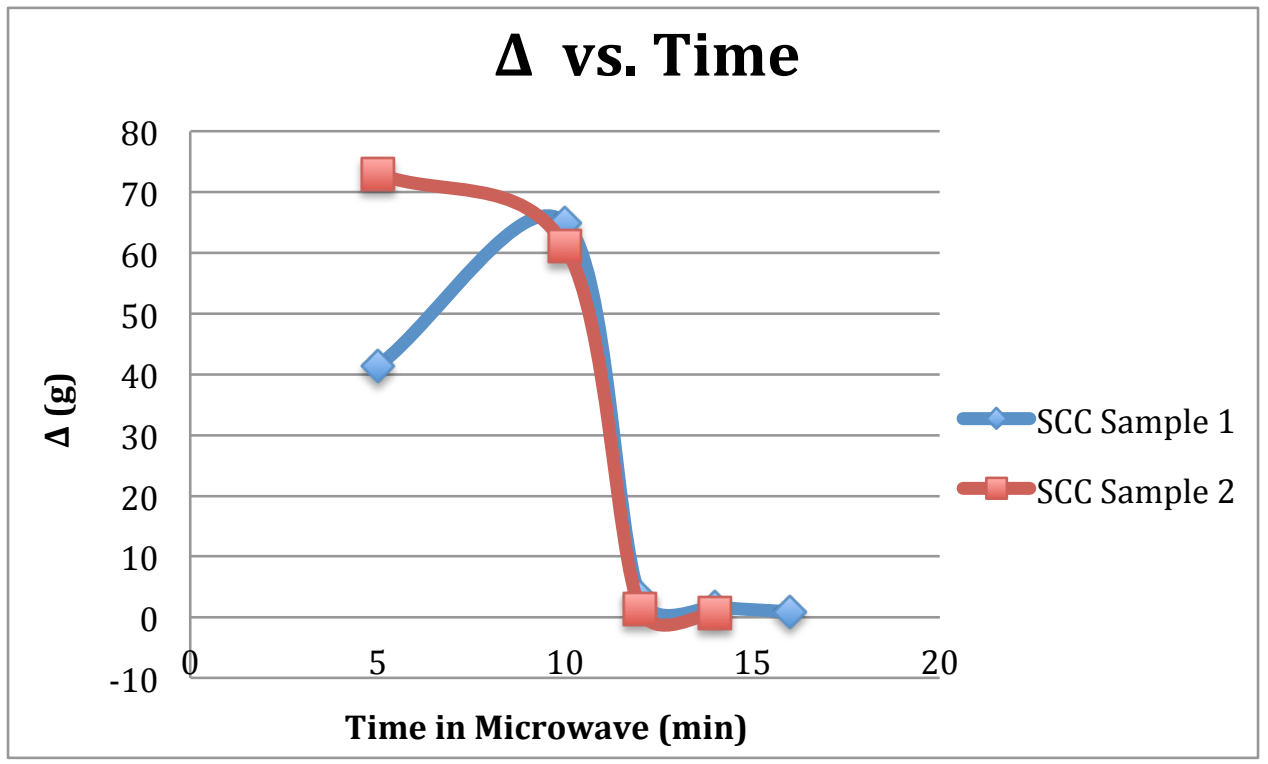

Figure 4.5 - Change in Weight vs. Microwave Time for SCC samples 


\subsection{UPV}

\subsubsection{Dynamic and Static Young's Modulus of Concrete}

Tables 4.1 and 4.2 show a comparison between the dynamic Young's modulus resulted from the ultrasonic pulse velocity test and the calculated static Young's modulus of concrete specimens for both Fly Ash and SCC. Its shown from the tables that the Young's modulus of SCC at 1 day of testing is higher than that of Fly Ash at 28 days. It can be observed from the tables that $\mathrm{E}_{\mathrm{s}}$ and $\mathrm{E}_{\mathrm{d}}$ don't match, the dynamic Young's modulus is much higher than the static Young's modulus; it is almost doubled. The dynamic Young's modulus resulted from the UPV test would always be the highest as mentioned earlier in chapter 2 . The relationship between the dynamic and static Young's modulus of concrete is not easily determined by analyzing its physical behavior due to the heterogeneity of concrete. The following equation was used to calculate the static Young's modulus based on the compressive strength of concrete specimens:

$E=57000 \sqrt{f^{\prime} c}$

Where:

$f^{\prime} c=$ Compressive Strength (psi)

Table 4.1 - Static and Dynamic Young's Modulus of Fly ash

\begin{tabular}{|c|c|c|c|c|}
\hline Day & $\begin{array}{c}\text { Measured } \\
\mathrm{f}^{\prime} \mathrm{c}(\mathrm{psi})\end{array}$ & $\begin{array}{c}\mathrm{E}_{\mathrm{c}}(\mathrm{Static}) \\
(\mathrm{psi})\end{array}$ & $\begin{array}{c}\mathrm{E}_{\mathrm{d}}(\text { Dynamic) } \\
(\mathrm{psi})\end{array}$ & $\mathrm{E}_{\mathrm{c}} \mathrm{E}_{\mathrm{d}}$ \\
\hline 1 & 1250 & $2.02 \mathrm{E}+06$ & $4.46 \mathrm{E}+06$ & 0.451 \\
\hline 3 & 2775 & $3.00 \mathrm{E}+06$ & $5.78 \mathrm{E}+06$ & 0.519 \\
\hline 7 & 3537.5 & $3.39 \mathrm{E}+06$ & $6.24 \mathrm{E}+06$ & 0.543 \\
\hline 14 & 4041.7 & $3.62 \mathrm{E}+06$ & $6.65 \mathrm{E}+06$ & 0.545 \\
\hline 28 & 4583.3 & $3.86 \mathrm{E}+06$ & $6.84 \mathrm{E}+06$ & 0.564 \\
\hline
\end{tabular}


Table 4.2 - Static and Dynamic Young's Modulus of SCC

\begin{tabular}{|c|c|c|c|c|}
\hline Day & $\begin{array}{c}\text { Measured } \\
\mathrm{f}^{\prime} \mathrm{c}(\mathrm{psi})\end{array}$ & $\begin{array}{c}\mathrm{E}_{\mathrm{c}}(\text { Static) } \\
(\mathrm{psi})\end{array}$ & $\begin{array}{c}\mathrm{E}_{\mathrm{d}}(\mathrm{Dynamic}) \\
(\mathrm{psi})\end{array}$ & $\mathrm{E}_{\mathrm{c}} / \mathrm{E}_{\mathrm{d}}$ \\
\hline 1 & 5000 & $4.03 \mathrm{E}+06$ & $6.08 \mathrm{E}+06$ & 0.663 \\
\hline 3 & 7958 & $5.08 \mathrm{E}+06$ & $6.86 \mathrm{E}+06$ & 0.742 \\
\hline 7 & 9125 & $5.44 \mathrm{E}+06$ & $7.27 \mathrm{E}+06$ & 0.749 \\
\hline 14 & 10000 & $5.70 \mathrm{E}+06$ & $7.29 \mathrm{E}+06$ & 0.782 \\
\hline 28 & 12500 & $6.37 \mathrm{E}+06$ & $7.37 \mathrm{E}+06$ & 0.864 \\
\hline
\end{tabular}

\subsubsection{The Relationship Between Compressive Strength and Wave Speed}

A correlation is set up and showed in Figures 4.6 and 4.7 with the data obtained from the experiment done on both Fly Ash and SCC using concrete specimens having dissimilar concrete mixture ratios. In order to develop a new correlation on concrete strength-UPV relationship, the curve that represents the experimental results produced from the ultrasonic velocity test and the curve that represents the calculated results produced in the laboratory are compared for both types of concrete; Fly Ash and SCC. The curves as shown in Figure 4.6 that represent that relationship for the calculated and experimental results of conventional concrete specimens are respectively given as:

$y=(3.0 E-11) x^{4}$

$y=(2.0 E-19) x^{6.1401}$

Where, $y(\mathrm{psi})$ and $x(\mathrm{~m} / \mathrm{sec})$ respectively represent the strength and velocity. $\mathrm{R}^{2}$ value was found to be 1 for the calculated curve and 0.998 for the experimental curve. The calculated curve represents the right relationship between compressive strength and the wave speed $\left(f^{\prime} c \sim V_{p}^{4}\right)$ according to equations 2 and 10 mentioned in Chapter 2. Both Fly Ash curves keep increasing with the velocity being increased as shown in Figure 4.6 below. 


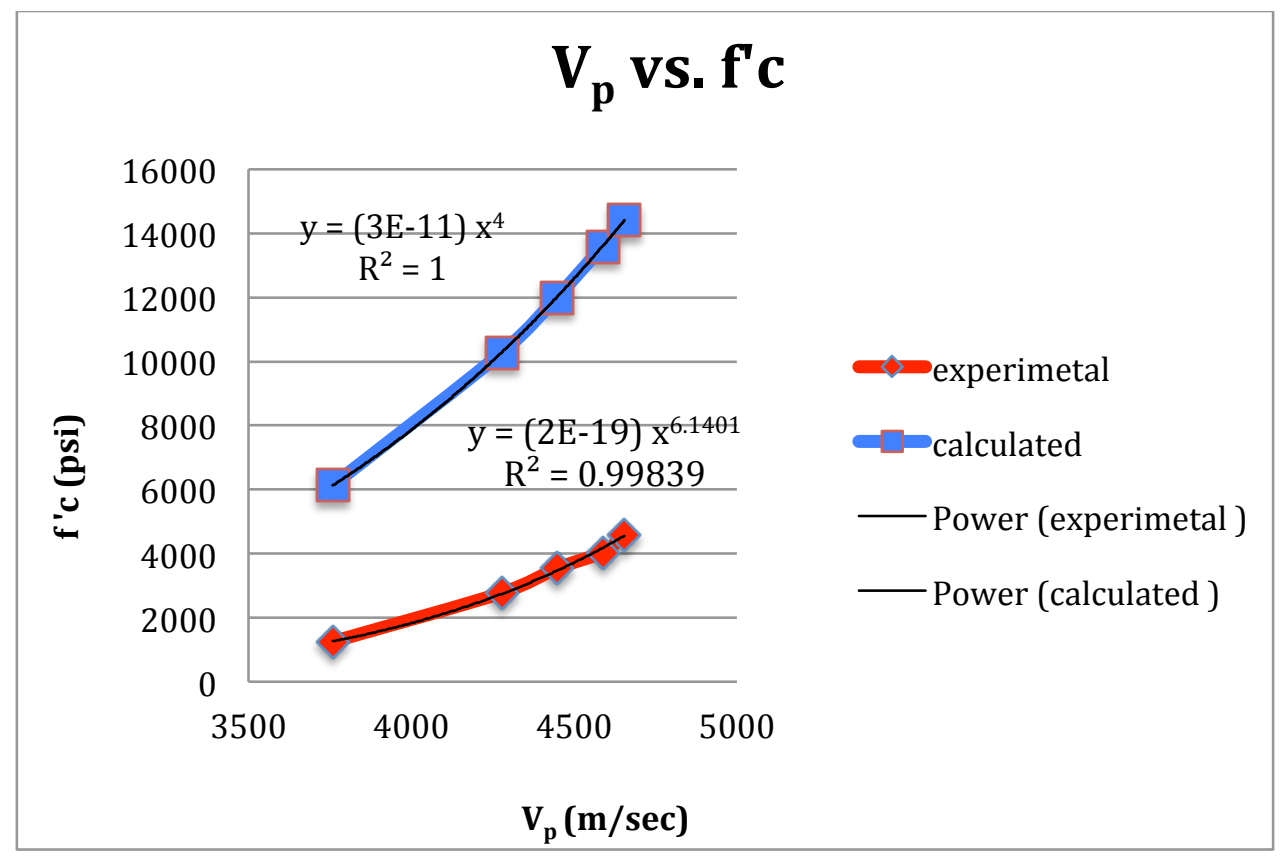

Figure 4.6 - Strength vs. wave speed of Fly Ash Concrete specimens

The curves shown in Figure 4.7 representing the relationship for the calculated and experimental results, respectively, of the self-consolidating concrete specimens are given as:

$y=(3.0 E-11) x^{4}$

$y=(7.0 E-27) x^{8.1912}$

Where, $y$ (psi) and $x(\mathrm{~m} / \mathrm{sec})$ respectively represent the compressive strength and the ultrasonic velocity. It is shown from Figure 4.7 that $\mathrm{R}^{2}$ value was found to be 1 for the calculated curve and 0.922 for the experimental curve. The calculated curve represents the right relationship as mentioned earlier for SCC results too. The calculated results match for both cases but the experimental results differ depending on the different mixture ratios. The curve obtained from calculated results of Fly Ash and the curve obtained from calculated results of SCC increase parallel as velocity increases. It shown from Figure 4.7 that the experimental curve went off 
which might be because the results at 7 and 14 days were too close to each other as the strength growth of the concrete specimens started to become constant.

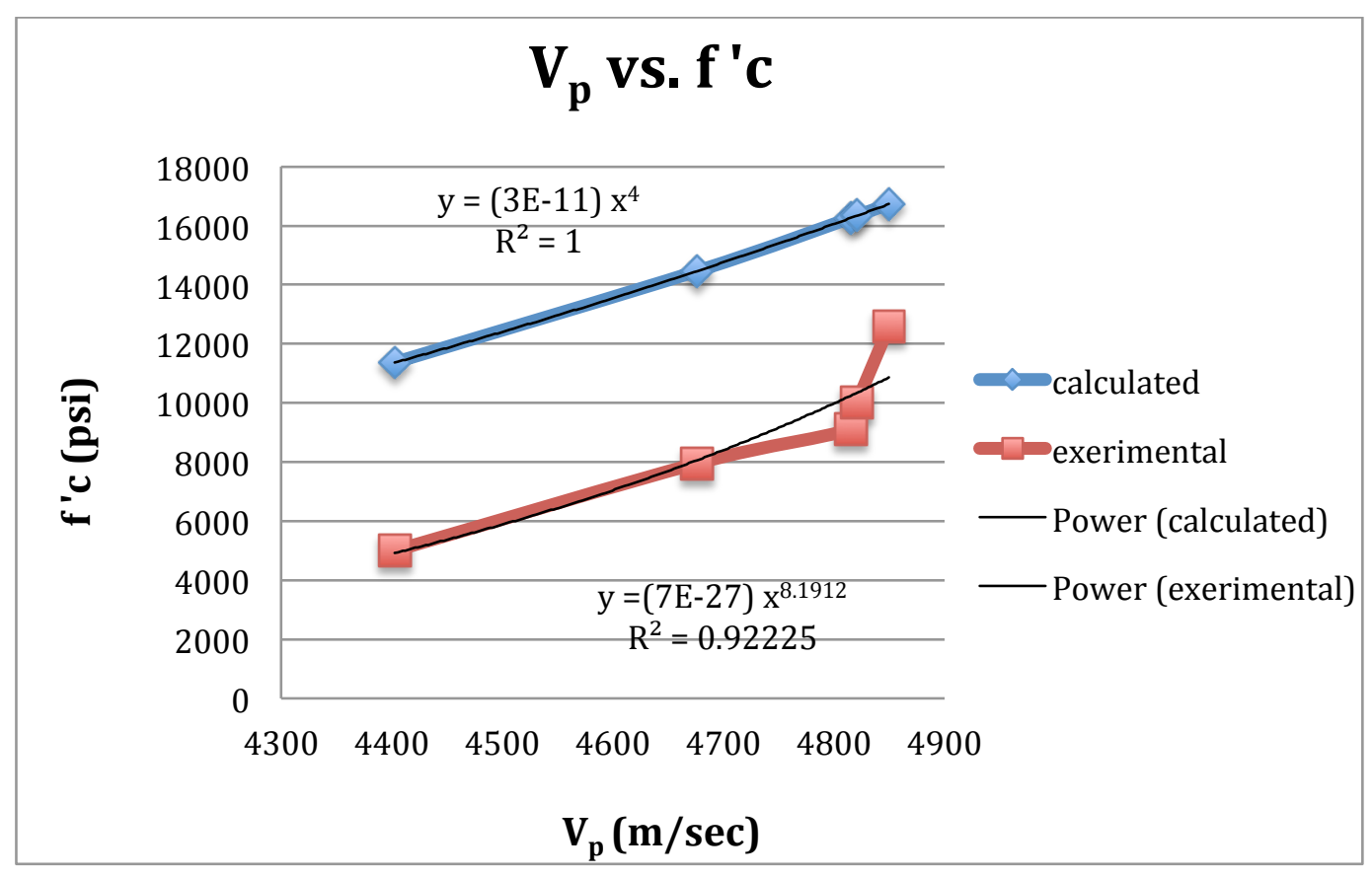

Figure 4.7 - Strength vs. wave speed of SCC specimens

Figure 4.8 shows the relationship between compressive strength and time $(1,3,7,14$, and 28 days of testing). It can be shown from the graph that SCC has a much higher compressive strength compared to normal concrete at the same days of testing the concrete specimens. The results for SCC are more than the double of the Fly Ash values. At day 1 of testing SCC specimen's compressive strength reaches 5000 psi, which is more than what Fly Ash specimen reaches at 28 days of testing. 


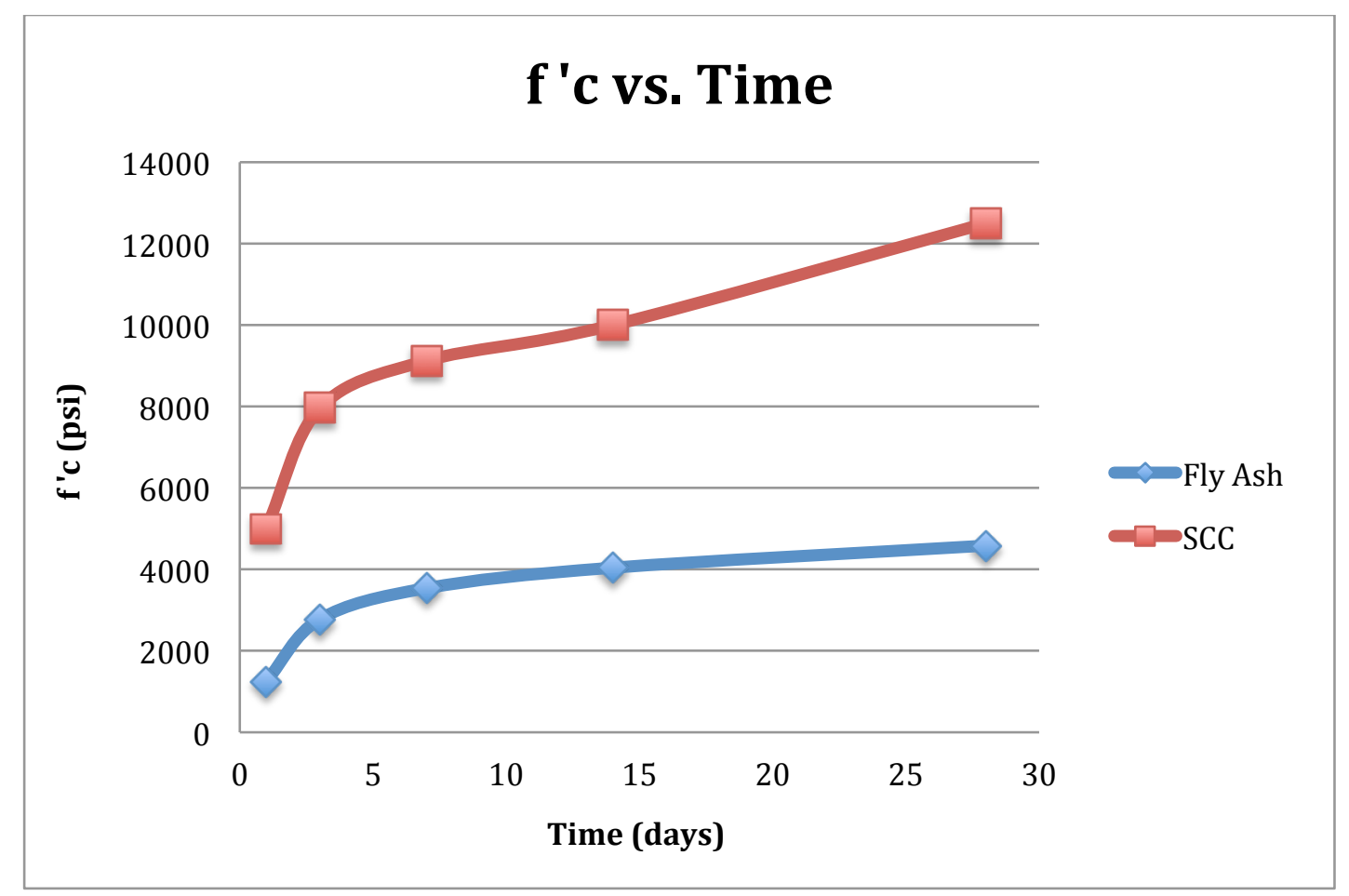

Figure 4.8 - Compressive Strength vs. Time

\subsubsection{FEM Modeling of Concrete Specimens Using ABAQUS}

ABAQUS software is used for FEM modeling for the purpose of this study. A concrete rectangular specimen was modeled in ABAQUS for both Fly Ash and SCC samples using their actual sizes and experimental properties resulted from the UPV test. Snap shot of the resulted model is given in Figures 4.9 and 4.10 for Fly Ash and SCC respectively. The experimental and FEM results such as stress distribution are compared. It can be shown from the Figures 4.9 and 4.10 below that the wave travel time matches from the experimental results and ABAQUS results. For the SCC model it is reaching $94 \mu \mathrm{s}$ and for the Fly Ash model it is reaching $110 \mu \mathrm{s}$, which are the same as what was produced from the experiment. 


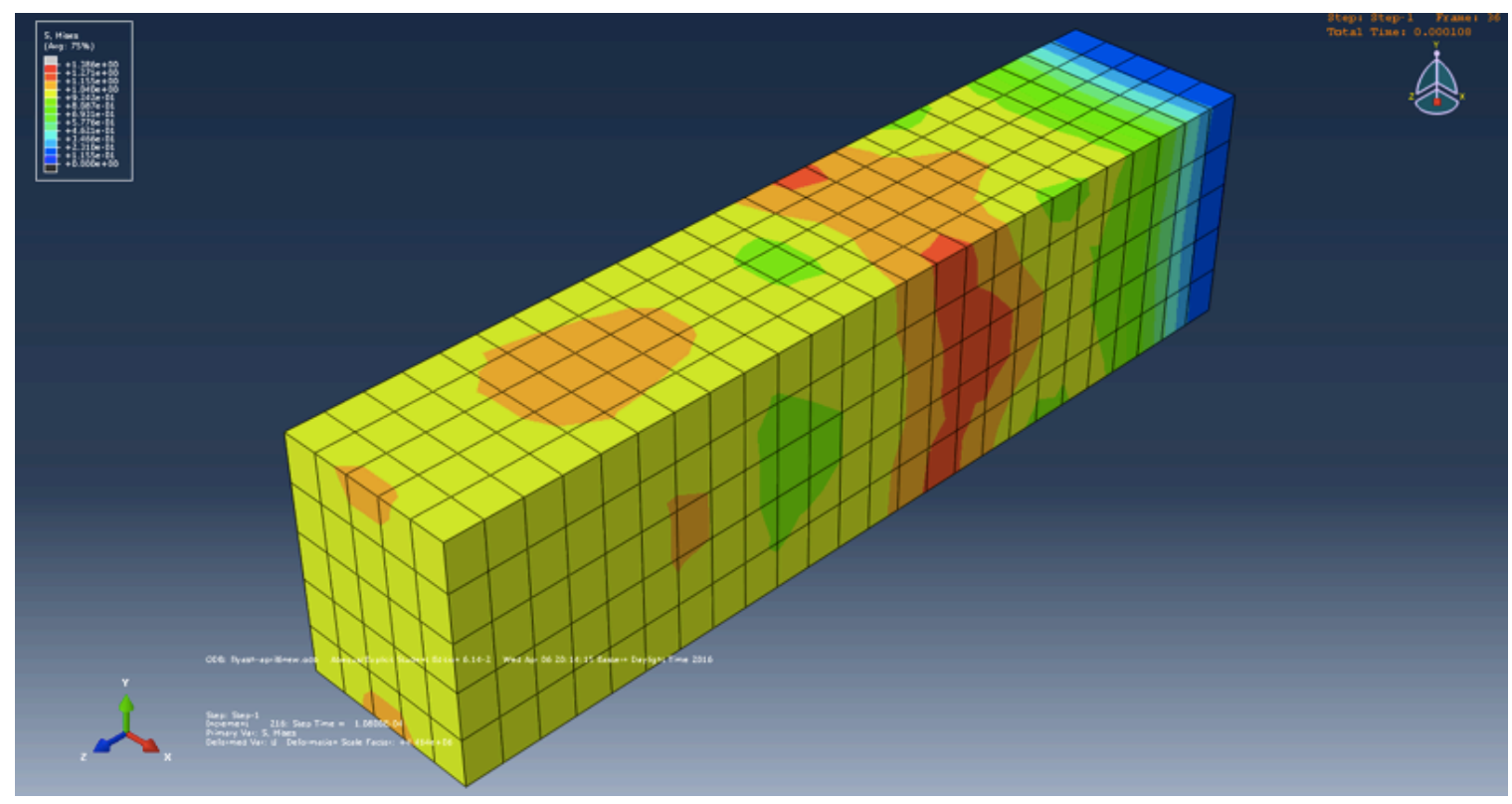

Figure 4.9 - Resulted model of Fly Ash specimen Using 25 Elements in ABAQUS

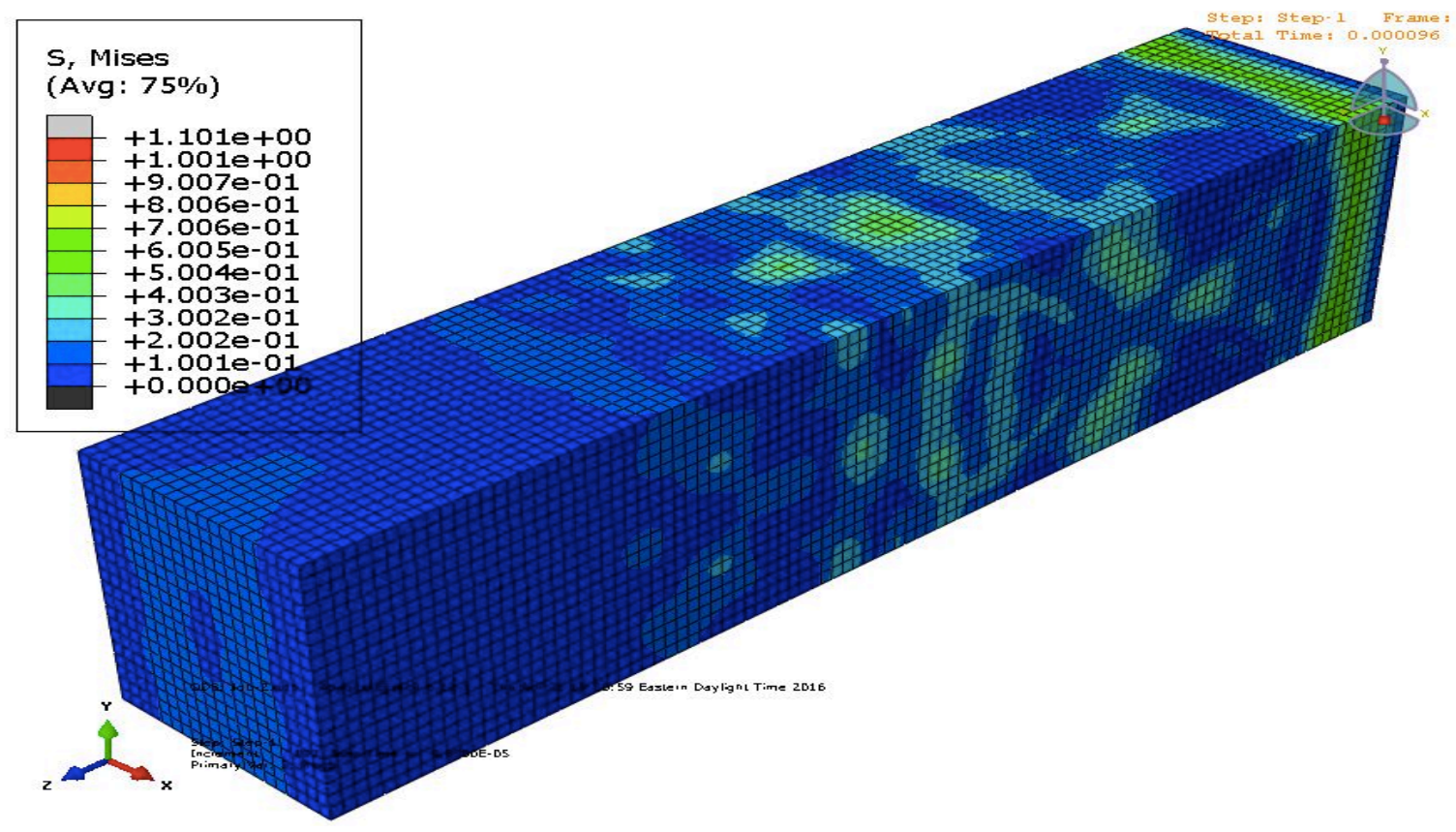

Figure 4.10 - Resulted model of SCC specimen Using 100 Elements in ABAQUS 
The SCC specimen was modeled with different number of elements to determine the difference between them and which number of elements would provide more accurate results. The graph shows the pulse propagating through the entire length of the specimen. For the purpose of this experiment 2 models have been made one with 25 elements and another with 100 elements mesh shown in Figure 4.12. The initial loading pulse function used in this model has a duration of $10 \mu$ s as shown in Figure 4.11 and the resulted wave travel time through the entire length of the specimen measured from the experiment is $94 \mu$ s, so with a total of 100 elements for the specimen length, the $10 \mu$ s pulse would have a wave length covering about 10 elements. But with a total of 25 elements for the entire length, the pulse wavelength would only cove 2 to 3 elements, so the wave propagation simulation was not performed well using only 25 elements. The duration of the initial loading function is $10 \mu \mathrm{s}$ with a peak at $5 \mu \mathrm{s}$, and the 100 -element model has a peak at $97.5 \mu$ s, so the arrival time of the wave is from peak to peak which would equal to $92.5 \mu \mathrm{s}$. Peak to peak measurements have been always applied when measuring the ultrasonic signals in bitscope as mentioned in previous chapters. As shown in Figure 4.12, the results show that using 100 elements, the wave propagating velocity can be calculated accurately using the current FEM model. 


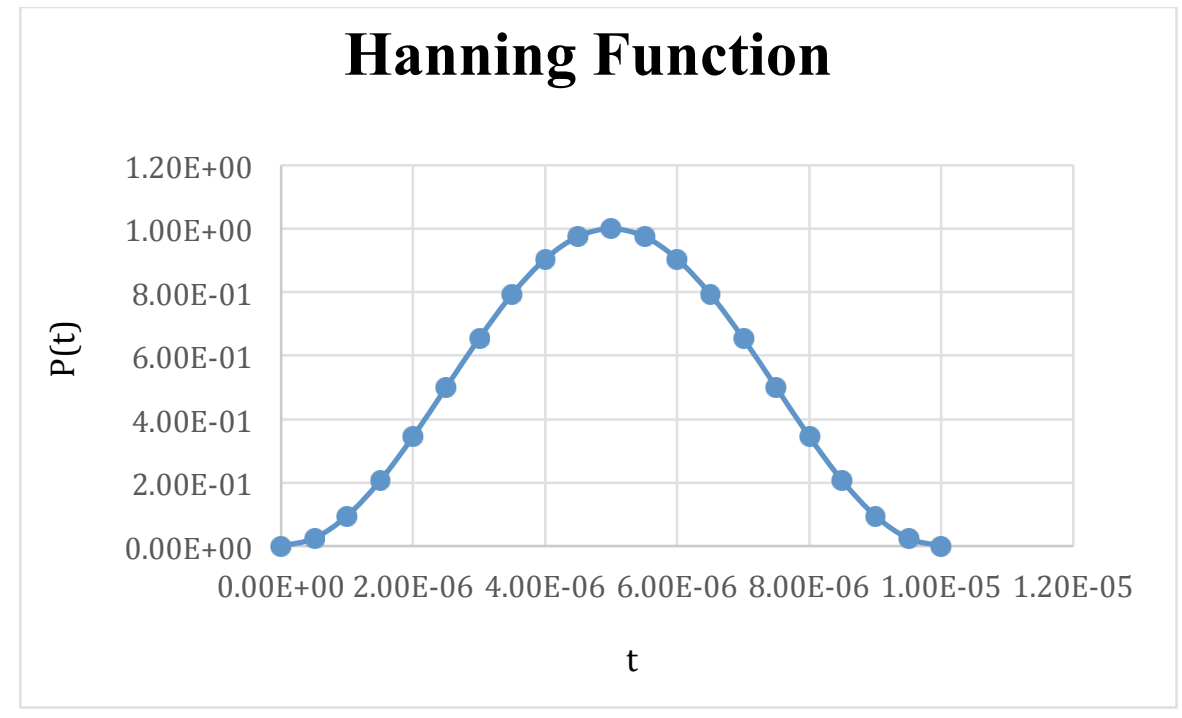

Figure 4.11 - Loading pulse function

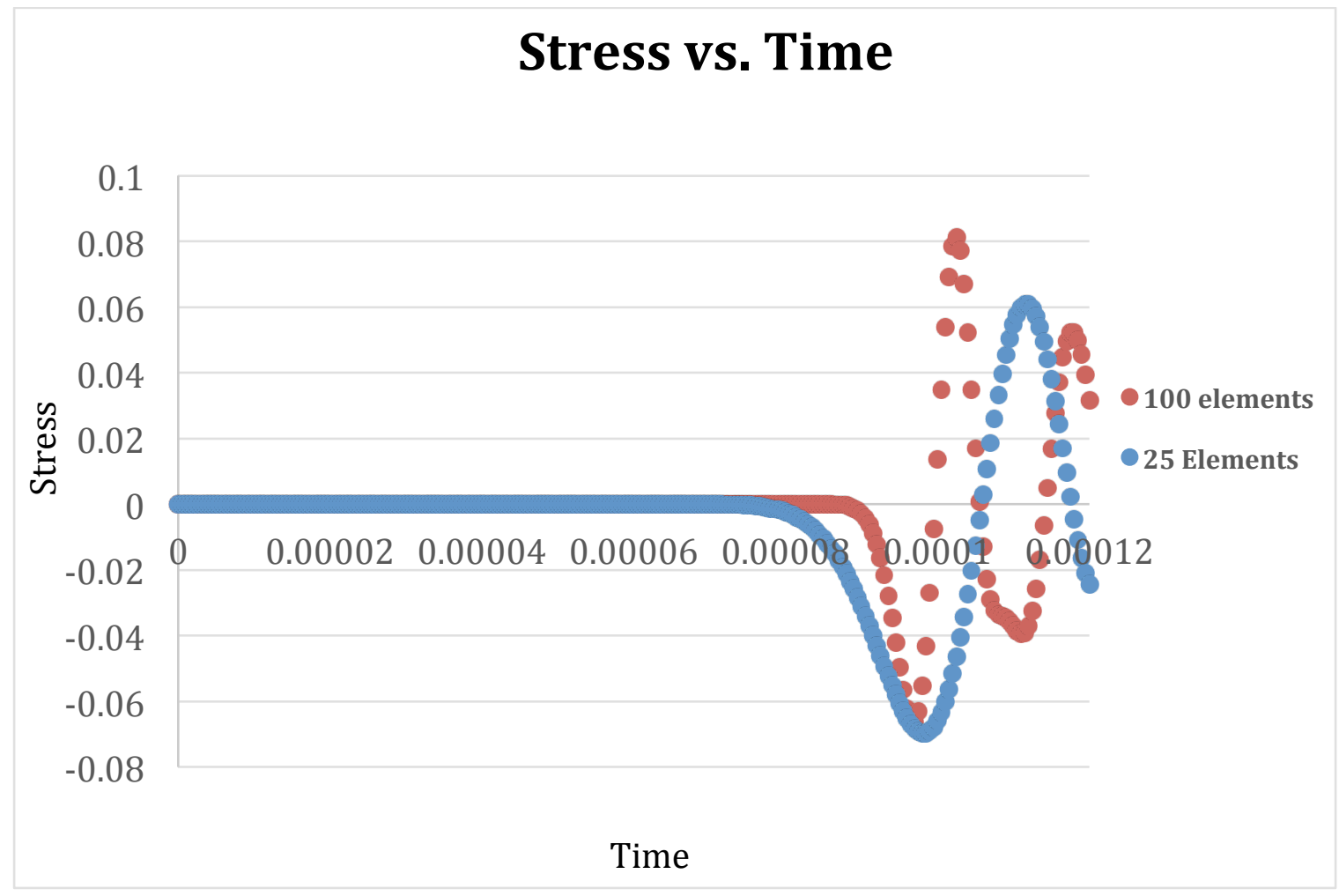

Figure 4.12 - ABAQUS results using 25 elements and 100 elements 


\section{CHAPTER 5: Conclusions and Recommendations}

\subsection{Determination of Water Cement Ratio Using Microwave Method}

In this thesis the standard method for water content of freshly mixed concrete using microwave method was tested on both conventional concrete and SCC to determine their on-site water to cement ratio. Two testing procedures were used following AASHTO T318-02, which included the use of concrete samples and sieved sample. Both methods were used to determine the w/c ratio for the conventional Fly Ash concrete and SCC with different accuracy ranges between the two. The average error for TVC is $5.13 \%$ and for SCC is $10.35 \%$ using non-sieved samples. However, the results showed that the current method using sieved samples would not provide accurate results.

The modified method using sieved samples for both SCC and conventional concrete samples provided higher \% error of $19.15 \%$ for Fly ash concrete sample and an average of 98.88 $\%$ for SCC. The reason why the sieved method provides an inaccurate result is that the amount of powder that is being extracted from the large aggregates and the sand particles of the sample is not the correct cement powder amount. It is hard to get all of the powder out of the large aggregates and sand particles. On the other hand, this method can be implemented for quality control use in the field for regular fly ash concrete mixes using non-sieved samples, providing promising and accurate results. Further research is being conducted to improve the sieved method which will provide more accurate results.

There is a concern with the method in calculating $\mathrm{w} / \mathrm{cm}$, which is the assumption of the uniform proportions when getting samples from the same batch of concrete mix. In addition, the assumption of moisture content of large aggregates is being recoverable. During this method the 
total free water of the mix was determined by reducing the SSD moisture of the large and small aggregates from the total evaporated water. The fact that the moisture content of fine aggregates is easily evaporated does not necessarily imply that this could be the case for large aggregates too. Further investigations should be done in order to determine if those assumptions are valid.

Due to the ease and technique availability of this testing and the potential of getting accurate results with some modifications, this method could be widely used in different applications to determine the $\mathrm{w} / \mathrm{cm}$ of freshly mixed concrete based on the provided mix design properties. Further research is needed to provide more information on whether this method could be done on different concrete mixtures.

\subsection{Ultrasonic Pulse Velocity Test}

This study shows that UPV test provides very important result that could relate to the conditions of concrete structures. Due to concrete's heterogeneity, it is hard to determine the relationship between UPV and strength of concrete since it is affected by w/c, type and size of aggregates and other variables. The results show that there is a good correlation between strength of concrete and UPV. It was concluded that there were some variations between the data resulted from different type of concretes such as: SCC and Fly Ash concrete. Those variations are resulted from the different $\mathrm{w} / \mathrm{c}$ ratios and different types and sizes of aggregates. Understanding the effect of the variations of tests conditions on UPV results decreases the error in estimating the strength of concrete.

It can be also concluded based on the FEM analytical models done using ABAQUS that the more number of elements is used the more accurate results can be obtained and that's because the wave length needs to be covered by enough elements in order to be able to propagate 
accurately. Less number of elements would not be able to produce an accurate wave propagation curve.

This research shows that UPV test is a sensitive tool that has the ability to analyze variations in density and homogeneity of concrete samples. It can be concluded that the UPV test is one of the tests that could be applied on concrete to detect deterioration and to enable the quality of concrete structures. 


\section{REFERENCES}

About concrete. (1995). Retrieved from nrmca:

http://www.nrmca.org/aboutconcrete/cips/26p.pdf

Al-Owaisy, L. S. (2006). Post Heat Exposure Properties of Steel Fiber Reinforced Concrete. . Journal of Engineering and Development.

Angel Vilanova, J. F.-G. (2012). Mechanical Properties of Self-Consolidating Concrete Using Conventional Concrete Models.

ASTM . (2009). Standard Test Method for Pulse Velocity Through Concrete. ASTM C597 - 09 . West Conshohocken: ASTM International.

ASTM. (2016). Standard Practice for Making and Curing Concrete Test Specimens in the Laboratory. ASTM C192 / C192M - 16. West Conshohocken, PA: ASTM International.

ASTM. (2016). Standard Specification for Ready-Mixed Concrete. ASTM C94 / C94M - 16 . West Conshohocken, PA: ASTM International.

ASTM. (2014). Standard Test Method for Air Content of Freshly Mixed Concrete by the Pressure Method. ASTM C231 / C231M - 14 . West Conshohocken, PA: ASTM International.

ASTM. (2016). Standard Test Method for Air Content of Freshly Mixed Concrete by the Volumetric Method. ASTM C173 / C173M . West Conshohocken, PA: ASTM International.

ASTM. (2011). Standard Test Method for Compressive Strength of Cylindrical Concrete Specimens. ASTM C39 / C39M - 11. West Conshohocken, PA: ASTM International.

ASTM. (2014). Standard Test Method for Passing Ability of Self-Consolidating Concrete by J-Ring. ASTM C1621 / C1621M . Standard Test Method for Passing Ability of SelfConsolidating Concrete by J-Ring, PA: ASTM Internationa.

ASTM. (2014). Standard Test Method for Rapid Assessment of Static Segregation Resistance of Self-Consolidating Concrete Using Penetration Test. ASTM C1712 - 14 . West Conshohocken: ASTM International.

ASTM. (2014). Standard Test Method for Slump Flow of Self-Consolidating Concrete. ASTM C1611 / C1611M - 14. West Conshohocken, PA: ASTM International.

ASTM. (2004). Standard Test Method for Splitting Tensile Strength of Cylindrical Concrete Specimens. ASTM C496 / C496M - 11. West Conshohocken, PA: ASTM International. 
ASTM. (2013). Standard Test Method for Total Evaporable Moisture Content of Aggregate by Drying. ASTM C566 - 13. West Conshohocken: ASTM International.

Berriman, J. P. (2005). Humidity and aggregate content correction factors for air-coupled ultrasonic evaluation of concrete.

Carino, N. J (2004). Nondestructive testing of concrete.

Civil Engineering . (2010, 06 13). Retrieved from civil resources : http://civilresources.blogspot.com/2010/06/self-compacting-concrete.html

Controlling water in self compacting concrete production. (2010). Retrieved from hydronix:

http://www.hydronix.com/downloads/articles/product_range/controlling_water_in_self_c ompacting_concrete.pdf

Curtis Badman, J. B. (2003). Interim Guidelines for the Use of Self-Consolidating Concrete in Precast/Prestressed Concrete Institute Member Plants . Precast/Prestressed Concrete Institute.

Druta, C. (2003). Tensile strength and bonding characteristics of self-compacting concrete .

Enad Mahmoud. A.-C. (2013). Self-Consolidating Concrete Incorporating High Volume of Fly Ash, Slag, and Recycled Asphalt Pavement. International Journal of Concrete Structures and Materials.

F. M. ALMEIDA FILHO, B. E. (2008). Variability of the bond and mechanical properties of self-compacting concrete. IBARCON structres and materials .

Fowler, E. P. (2007). Inspection manual for self -consolidating concrete in precast members . Center for Transportation Research The University of Texas at Austin.

Gebretsadik, B. T. (2003). Ultrasonic pulse velocity in vestigation of steel fiber reinforced self-com pacted concrete . Ethiopia: Department of Civil and E nvironmental Engineering Howard R. Hughes College of Engineering The Graduate College .

Gebretsadik, B. T. (2013). Ultrasonic Pulse Velocity Investigation of Steel Fiber Reinforced Self-Compacted Concrete. UNLV Theses/Dissertations/Professional Papers/Capstones, Paper 1828.

Hajime Okamura, M. O. (2003). Self-Compacting Concrete. Journal of Advanced Concrete Technology.

Halliday, D. a., Resnick, R., Walker J. (1970). Fundamentals of Physics. John Wiley \& Sons, Inc. 
Hershberger, J. (2015). A study of self consolidating concrete for cast in place applications: current practices, rapid $\mathrm{w} / \mathrm{cm}$ determination, and stability effects of pumping. Master Thesis, Department of Civil and Environmental Engineering, West Virginia University.

Hurd, M. (2002). Self-Compacting Concrete. Concrete Construction, Vol. 47, No. 1.

I. Lawson, K. D. (2011). Non-Destructive Evaluation of Concrete using Ultrasonic Pulse Velocity.

Ikpong A.A. (1993). The relationship between the strength and non-destructive parameters of rice husk ash concrete. Cement and Concrete Research, Vol. 23, pp. 387-398

James Instruments INC. , James Cementometer. Retrieved from ndtjames: http://www.ndtjames.com/v/vspfiles/downloadables/Cementometer_Complete_Data.pdf

Ismail Ozgur Yaman, G. I. (2001). Ultrasonic Pulse Velocity in Concrete Using Direct and Indirect Transmission. ACI Materials Journal

Jones, R. (1962). Non-Destructive Testing of Concrete. London.

Jones, R. (1954). Testing of concrete by an ultrasonic pulse technique, RILEM Int. Symp. on Nondestructive Testing of Materials and Structures. Paris.

Jung, E. P. (2007). Self-Consolidating Concrete for Precast Structural Applications: Mixture Proportions, Workability, and Early-Age Hardened Properties . Texas Department of Transportation.

K.S. Pann, T. Yen, C. Tang and T. D. Lin (2003), A New Strength Model Based on Water/ Cement Ratio and Capillary Porosity . ACI Material Journal, 100, 4, 311-318.

Kangvanpanich, K. (2002). EARLY AGE CREEP OF SELF - COMPACTING CONCRETE USING LOW HEAT CEMENT AT DIFFERENT STRESS/STRENGTH RATIOS. Department of Infrastructure System Engineering, Kochi University of Technology

Kaouther, J. M. (2014). Destructive and Non-destructive Testing of Concrete Structures. jordan: Jordan Journal of Civil Engineering.

Kaplan, M. (1959). The effects of age and water to cement ratio upon the relation between ultrasonic pulse velocity and compressive strength of concrete. Mag. Concr. Res., 11(32), 85

Kazumasa OZAWA, K. M. (1992). Development of High Performance Concrete.

Malhotra, V. M. and Carino, N. J. (2004). Handbook on nondestructive testing of concrete. ASTM International, CRC Press. 
Manoj R. Vyawahare 1, M. V. (2015). The strength and durability investigations of powder type and VMA type self-consolidating concrete .

Marian Sab, T. O. (2012). Hardened properties of self-compacting concrete.

Nasr-Eddine Bouhamou, N. B. (2013). SHRINKAGE BEHAVIOR OF A SELF-COMPACTING CONCRETE. LCTPE Laboratory, Civil Engineering Department, University of Mostaganem, Algeria

Neuwald, A. D. (2010, may 28). Water-to-Cement Ratio and Aggregate Moisture Corrections. Retrieved from NPCA: http://precast.org/2010/05/water-to-cement-ratioand-aggregate-moisture-corrections/

O. R. KHALEEL 1a, S. A.-M. (2011). The Effect of Coarse Aggregate on Fresh and Hardened Properties of Self-Compacting Concrete (SCC) .

Ontario, R. M. (2009). Best Practices Guidelines for Self - Consolidating Concrete.

Ouchi, N. O. (2003). Applicat ions of self-compacti n g concret e in japan, europe and the united states.

Palmer, B. (n.d.). Self-Consolidating Concrete. Retrieved from concretenetwork: http://www.concretenetwork.com/self-consolidating-concrete/

Palmer, B. (n.d.). What is Self-Consolidating Concrete? . Retrieved from concretenetwork: http://www.concretenetwork.com/self-consolidating-concrete/

Peterson, K. W. (2011). Impact of Hydrated Cement Paste Quality and Entrained Air - Void System on the Durability of Concrete. Michigan Department of Transportation

Popovics, J. S. (2008). A Study of Static and Dynamic Modulus of Elasticity of Concrete. Civil \& Environmental Engineering, University of Illinois, Urbana, IL

R, N. T. (1987). Variations in Concrete Strength. Presented at the ACI Annual Convention, San Antonio

Rajeev, D. S. (2012). Development of Self Compacting Concrete by use of P ortland Pozzolana Cement, Hydrated Lime and Silica Fume. ISCA Journal of Engineering Sciences. 
ramme, t. r. (1989). determination of the water - cement ratio of concrete by the buoyancy principle. Department of civil engineering and Mechanics College of engineering and applied science the university of wisconsin, milwaukee

Rebelo, J. (2014). Evaluation of Test Methods for Determining the Water to Cement Ratio of Fresh and Hardened Concrete. University of Toronto

Self Consolidating Concrete. (2004). Concrete in Practice. What, Why \& How? http://www.nrmca.org/aboutconcrete/cips/

Specification, Production and Use. $(2005,05)$. Retrieved from The European Guidelines for Self-Compacting Concrete :

http://www.europeanconcrete.eu/images/stories/publications/en_guidelines.pdf?phpMy Admin=16bbb563ca43adfed14bd78eb7d8cd8a

Supplementary cementitious materials. (2009). Retrieved from sustaiable concrete : http://www.sustainableconcrete.org/?q=node/142

Tarun R. Naik, Y. -m. (2004).DEVELOPMENT OF HIGH - STRENGTH SELF - CONSOLIDATING CONCRETE. 2004: Department of Civil Engineering and Mechanics College of Engineering and Applied Science THE UNIVERSITY OF WISCONSIN - MILWAUKEE.

Technology, m. u. (2012). Final Report Prepared for Missouri Department of Transportation 2012 August Project TRyy1103 Report cmr 13 - 003 Self - Consolidating Concrete (SCC) for Infrastructure Elements Report E - Hardened Mechanical Properties and Durability Performance. Missouri Department of Transportation Construction and Materials .

Trtnik G., K. F. (2009). Prediction of concrete strength using ultrasonic pulse velocity and artificial neural networks Ultrasonics.

Turici, B. M. (2013, 04 08). Adding Water to Concrete. Retrieved from concreteconstruction: http://www.concreteconstruction.net/moisture-inconcrete/adding-water-to-concrete.aspx

Ultrasonic Couplants. (n.d.). Retrieved from olympus-ims: http://www.olympusims.com/en/applications/ultrasonic-couplant/

Ulucan Z. C.., T. K. (2008). Effect of mineral admixtures on the correlation between ultrasonic velocity and compressive strength for selfcompacting concrete. Russian Journal of Nondestructive Testing. 
Umar, A. ALtimimi, A.. (2011). Influence of Viscosity Modifying Admi xture (VMA) on the Properties of SCC Produced Using Locally Supplied Materials in Bahrain. College of Engineering, University of Bahrain, Bahrain, arshad_umar@rediffmail.com.

Weibe, F. D. (2000). Self-Compacting Concrete (SCC) Time Development of the Material Properties and the Bond Behaviour .

Ye, G. L. (2004). Study on the development of the microstructure in cement-based materials by means of numerical simulation and ultrasonic pulse velocity measurement. 


\section{VITA}

My name is Dana Jassim Dashti, and my home country is Kuwait where the first language is Arabic and the second language is English. I was born on March 9, 1992 in Kuwait and I am the only girl between three brothers. I graduated from high school in Kuwait in 2009 and then applied for WVU school of Engineering and moved to Morgantown in 2010 for college. I got my bachelor's degree in Civil Engineering from WVU in May 2014 and then applied immediately for the graduate program at WVU school of Engineering. I got my master degree in Civil Engineering in May 2016. 